\title{
ANIMALES REPRESENTADOS Y ANIMALES CAZADOS: APORTES PARA EL ESTUDIO ARQUEOLÓGICO DE LA INTERACCIÓN SIMBÓLICA HUMANOS-FAUNA ENTRE LOS CAZADORES-RECOLECTORES COMPLEJOS DE LAS TIERRAS BAJAS DEL PARANÁ (ARGENTINA)
}

\author{
DEPICTED ANIMALS AND HUNTED ANIMALS: CONTRIBUTIONS \\ TO THE ARCHAEOLOGICAL STUDY OF HUMAN-ANIMAL SYMBOLIC \\ INTERACTION AMONG THE COMPLEX HUNTER-GATHERERS \\ FROM THE PARANÁ RIVER LOWLANDS (ARGENTINA)
}

\author{
Flavia V. Ottalagano ${ }^{1,2}$
}

\begin{abstract}
En este trabajo se identifican taxonómicamente 191 motivos zoomorfos de cerámica provenientes de las tierras bajas del Río Paraná (nordeste de Argentina), para luego comparar este registro iconográfico con el registro zooarqueológico disponible, a fin de cotejar los animales representados en el arte prehispánico con aquellos efectivamente consumidos. La muestra analizada procede de colecciones de museo y excavaciones propias, y fue recuperada en sitios ocupados por cazadores-recolectores complejos cuyo rango cronológico oscila entre los $1056 \pm 47$ y $488 \pm 24$ años ${ }^{14} \mathrm{C}$ AP. Los resultados indican una discordancia entre la fauna habitualmente explotada como recurso alimenticio (peces, pequeños roedores y cérvidos) y aquella frecuentemente representada en la iconografía (aves, felinos, carpinchos y ofidios). Este estudio intenta aportar al conocimiento de la interacción humano-animal y profundizar acerca de los roles simbólicos de algunas especies faunísticas entre las sociedades de pequeña escala que habitaron el área durante el Holoceno Tardío.
\end{abstract}

Palabras claves: iconografía cerámica, representaciones zoomorfas, simbolismo animal, tierras bajas del Paraná, Holoceno Tardío.

In this paper, 191 ceramic zoomorphic motifs from the lowlands of the Paraná River (northeastern Argentina) are taxonomically identified. Subsequently, this iconographic record is compared with the available zooarchaeological record to contrast the animals depicted in pre-Hispanic art with those actually consumed. The sample analyzed, obtained from museum collections and author excavations, was recovered from complex hunter-gatherer sites dating from between $1056 \pm 47$ and $488 \pm 24$ years ${ }^{14} \mathrm{C} \mathrm{BP}$. The data show discordance between the animals routinely hunted for food (fish, small rodents, and deer) and those frequently portrayed in the pre-Hispanic ceramic (birds, felines, capybaras, and ophidians). This analysis attempts to further our understanding of human-animal interaction and to delve into the symbolic roles that some faunal species played in the small-scale societies that inhabited the area during the Late Holocene.

Key words: Ceramic iconography, zoomorphic representations, animal symbolism, lowlands of the Paraná River, Late Holocene.

Las interacciones entre humanos y fauna es un eje central a considerar en el estudio de las sociedades prehispánicas. Los animales no solo constituyen una base para la alimentación, la confección de instrumentos o la vestimenta, sino que también pueden estar incorporados al entorno social y familiar como mascotas, o ser partícipes de rituales y tabúes (Arluke et al. 2015). Los animales conforman, particularmente, una fuente primordial de significados simbólicos para las sociedades. Las formas zoológicas son empleadas como un importante recurso metafórico para pensar el mundo humano (Foster 1994; Ingold 1994; Lévi-Strauss 1997; Willis 1990). Las interacciones simbólicas entre humanos y fauna suelen hacerse explícitas a través del mito, el rito y las manifestaciones artísticas. El arte posee cualidades representacionales y comunicacionales

\footnotetext{
1 Consejo Nacional de Investigaciones Científicas y Técnicas (CONICET), Ciudad de Buenos Aires, Argentina.

2 Instituto Nacional de Antropología y Pensamiento Latinoamericano, Ciudad de Buenos Aires, Argentina. flaviaott7@gmail.com
}

Recibido: marzo 2020. Aceptado: mayo 2020.

http://dx.doi.org/10.4067/S0717-73562021005000701. Publicado en línea: 16-junio-2021. 
(Layton 1991; Morphy 1994), y puede ser entendido como expresión activa de símbolos que son compartidos, negociados y vinculados con prácticas interpersonales en un determinado contexto socio-cultural (Hodder 1982a; Shanks y Hodder 1998).

El zoomorfismo es un tópico altamente recurrente en el arte prehispánico tanto sudamericano como mundial, y el intento por reconocer las especies representadas ha generado un continuo interés (Bernáldez-Sánchez y García-Viñas 2019; Berenguer 1996; Cornero 2019; Flores y Velárdez Fresia 2018; Gomes 2001; Gordillo 2009; Masseti 2003; Moreno 2019; Rangel Estrada 2014; Recalde y Colqui 2019; entre muchos otros). En la arqueología de las tierras bajas del Paraná, la iconografía zoomorfa está presente únicamente en la cerámica, ya que el arte rupestre y lítico están ausentes en el área media y baja de la cuenca, y tampoco hay registros de arte figurativo sobre hueso o asta. Esta iconografía fue considerada el aspecto central del estilo cerámico Goya-Malabrigo (González 1977; Serrano 1972), y está compuesta principalmente por apéndices modelados, adosados a recipientes de distintas morfologías y tamaños. La representación se limita usualmente a la cabeza del animal y en muy pocas ocasiones se extiende hacia el diseño completo del cuerpo. A diferencia de otros sistemas iconográficos donde las formas zoológicas se vinculan en escenas (sensu Gradin 1978), aquí se observan figuras unitarias que representan un solo animal. No obstante, algunas escasas excepciones pueden verse en aquellos casos donde se registran: dos apéndices idénticos en un mismo recipiente, un apéndice compuesto por dos animales morfológicamente independientes o en las figuras mixtas (ver discusión más adelante).

La búsqueda por comparar los motivos zoomorfos de la cerámica Goya-Malabrigo con la fauna local fue una inquietud temprana (Badano 1946; Gaspary 1950; González 1977; Outes 1918; Serrano 1946, 1961), pero que sin embargo no se realizó de manera sistemática. Una primera aproximación metódica a la identificación taxonómica se desarrolló en Ottalagano $(2008,2013)$, que fundamentalmente se centró en el reconocimiento de especies y géneros dentro la Familia Psittacidae, que son las aves más abundantes en la iconografía. Los demás motivos zoomorfos, en tanto, fueron clasificados en grandes categorías taxonómicas, sin efectuar un reconocimiento zoológico más preciso.

Este trabajo, por consiguiente, tiene un doble propósito. Por un lado, identificar con el mayor nivel de precisión taxonómica posible y mediante criterios sistemáticos, las distintas formas animales presentes en la iconografía analizada, teniendo en cuenta todas las macro categorías taxonómicas. Y, por el otro, comparar este registro iconográfico con los datos zooarqueológicos disponibles, de modo tal de confrontar los animales representados en el arte con aquellos efectivamente consumidos. Con esto se intenta aportar hacia el complejo entramado de interacciones entre humanos y fauna, que se dan particularmente al interior de sociedades de pequeña escala. Se inserta, por consiguiente, dentro del debate general acerca de los diferentes roles supra nutricionales desempeñados por los animales entre las poblaciones prehispánicas, así como de los caminos metodológicos desarrollados por la arqueología para evidenciarlos, donde la utilización conjunta de distintos registros constituye una herramienta clave (Arbuckle y McCarty 2015; Criado Boado y Penedo Romero 1989; Ryan y Crabtree 1995; Willis 1990; Zimmermann Holt 1996). Para ello, se considera una muestra altamente representativa de la iconografía Goya-Malabrigo, proveniente de colecciones de museo, trabajos de investigación realizados por otros investigadores y excavaciones propias, la cual fue recuperada en sitios que históricamente se han destacado como referentes de la arqueología de la región nordeste de Argentina (Ceruti y González 2007; Serrano 1972 ).

\section{Contexto Ambiental}

Los sitios arqueológicos incluidos en este trabajo se localizan en el Paraná medio (Figura 1), y se insertan en la ecorregión denominada Delta e Islas del Paraná (Burkart et al. 1999). La cuenca media del Río Paraná constituye una amplia y compleja llanura de inundación, la cual se extiende a lo largo de 600 $\mathrm{km}$. Está conformada por múltiples cursos fluviales, lagunas de escasa profundidad, islas y humedales. El área es considerada un importante eslabón de la cadena fluvial, la cual permite transportar grandes volúmenes de sedimentos y nutrientes desde el continente hacia el Océano Atlántico (Iriondo et al. 2007). La lluvia suele ser abundante durante todo el año (ca. 1.000 $1.200 \mathrm{~mm}$ por año), aunque se intensifica durante los meses de verano (Strahler 1975). Las condiciones de alta humedad, así como las reducidas variaciones en los niveles de temperatura diarios y estacionales, favorecen el desarrollo de especies cuyo hábitat característico se encuentra en puntos más septentrionales del corredor 


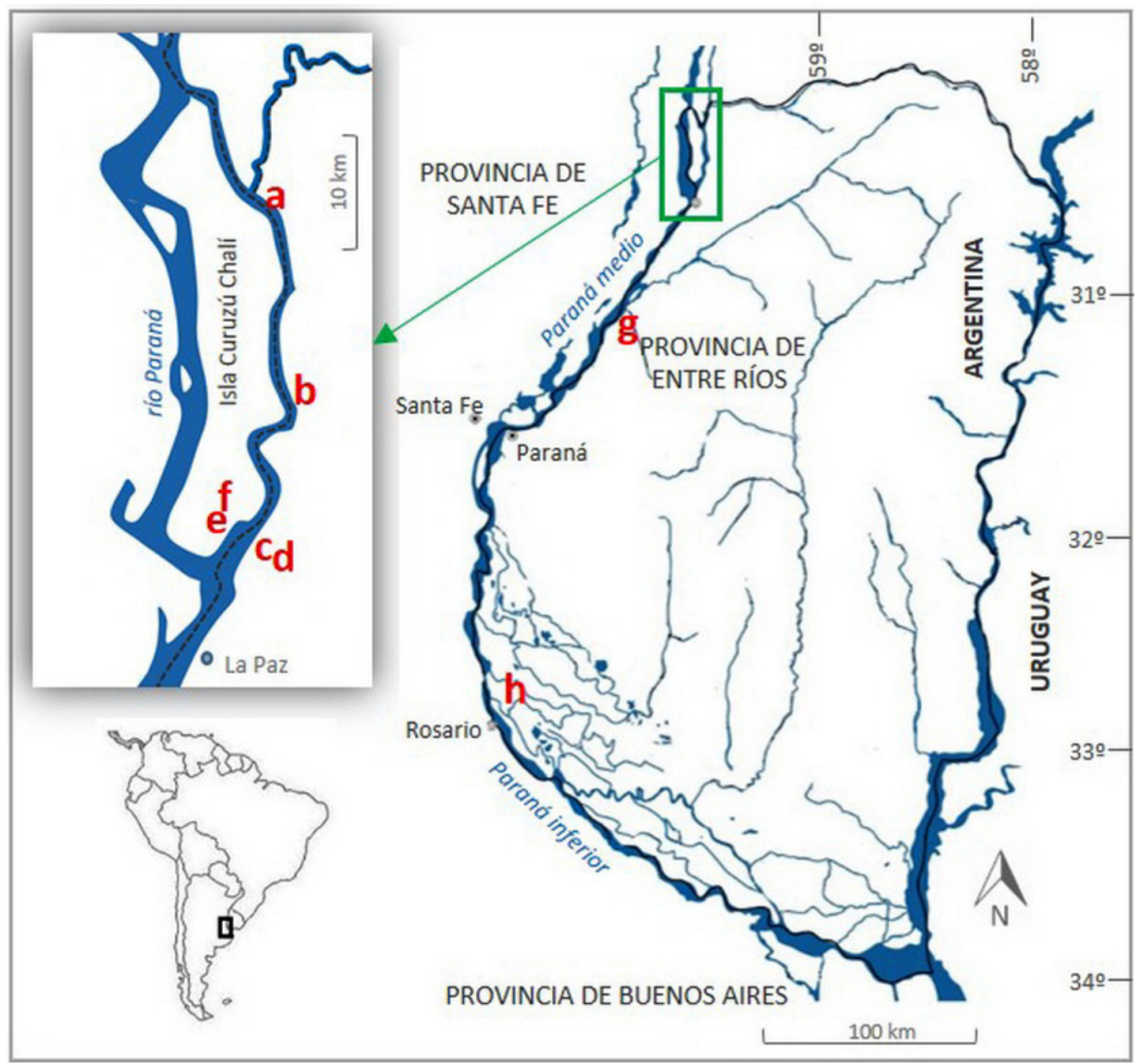

Figura 1. Localización de los sitios arqueológicos considerados: (a) PC1; (b) ALM1; (c) AA1; (d) AA4; (e) AL1; (f) AL5; (g) LP2; (h) CPA.

Locations of the archaeological sites considered: (a) PC1; (b) ALM1; (c) AA1; (d) AA4; (e) AL1; (f) AL5; (g) LP2; (h) CPA.

paranaense. Por lo tanto, la fauna y la flora del área son típicas de un ambiente de bosque en galería subtropical, las cuales coexisten con aquellas propias de los ecosistemas adyacentes (Burkart et al. 1999). La conformación del clima actual se estableció hace alrededor de un milenio antes del presente (Iriondo 1991), periodo en el cual corresponden cronológicamente los sitios arqueológicos incluidos en este estudio.

\section{Contexto Arqueológico y Registro Cerámico}

La iconografía zoomorfa analizada en este trabajo procede de sitios multipropósito vinculados a la entidad arqueológica Goya-Malabrigo (sensu Ceruti 2003), cuyo registro arqueológico fue generado por grupos cazadores-recolectores complejos durante el último tramo del Holoceno tardío. La dieta de estos grupos se basó principalmente en recursos provenientes de la pesca (p.ej., Pterodoras granulosus: armado, Pimelodus sp.: bagre, Prochilodis lineatus: sábalo), pero también de la caza de pequeños roedores (principalmente Myocastor coypus: coipo) y de algunos cérvidos (p.ej., Blastocerus dichotomus: ciervo de lo pantanos, Ozotoceros bezoarticus: venado de las pampas y Mazama gouazoubira: corzuela). Su alimentación también incorporó un consumo menor de plantas silvestres, domésticas o potencialmente 
manipulables (Bastourre 2014; Bonomo et al. 2011; Ceruti y González 2007; Colobig y Ottalagano 2016; Mucciolo y Pérez Jimeno 2015; Ottalagano 2019a, 2019b; Ottalagano y Loponte 2017; Píccoli et al. 2017; Santiago 2004; entre otros).

La cerámica proveniente de los sitios arqueológicos incorporados en este trabajo, se compone principalmente por recipientes abiertos (p.ej., platos, vasos, cuencos y escudillas) y cerrados (p.ej., ollas) (sensu Balfet et al. 1983), en los cuales predominan las formas globulares de contornos simples (sensu Shepard 1956). Alrededor de un 20\% de las vasijas se encuentran decoradas, ya sea por medio de técnicas de pintura, incisión y/o modelado figurativo. La tecnología cerámica tuvo un rol destacado en la subsistencia indígena. Fue empleada en buena medida para el procesamiento, almacenamiento y la cocción de los alimentos, como lo sugiere el estudio arqueométrico de los residuos absorbidos y adheridos en el interior, tanto de vasijas lisas como decoradas (Colobig y Ottalagano 2016; Ottalagano 2010, 2013, 2019b). Además de estos recipientes, los conjuntos cerámicos Goya-Malabrigo incluyen también una clase particular de artefacto: las "campanas". Esta denominación fue mencionada por Gaspary (1950) para referirse a piezas de morfología cónica o cilíndrica, con la presencia de una abertura basal. Los orificios basales suelen superar en diámetro a aquellos que conforman la boca del artefacto, otorgando un aspecto comparable al de una campana. Las paredes de estas piezas son notoriamente gruesas, lo que ha llevado a designarlas alternativamente como "alfarerías gruesas", concepto utilizado por Serrano (1946, 1972). Generalmente poseen un gran apéndice frontal zoomorfo que representa la cabeza, el cual se opone a un apéndice posterior más pequeño que representa las plumas caudales de un ave. También es común que se hayan modelado alas a los costados de la pieza (Ceruti 2003). Si bien la funcionalidad de los artefactos "campana" está actualmente bajo discusión, algunas evidencias sugieren un uso mortuorio (ver un resumen en Loponte et al. 2019).

Las figuras zoomorfas constituyen apéndices tanto de "campanas" como de vasijas abiertas y cerradas, como por ejemplo, platos, cuencos, escudillas y ollas. Asimismo, se encuentran presentes en las miniaturas, las cuales son reproducciones exactas a escala reducida de formas cerámicas de registro habitual en el área, como aquellas recién mencionadas (Gaspary 1950; Ottalagano 2020; Serrano 1946). De manera excepcional, el arte zoomorfo se desarrolló en adornos personales, como en el colgante de alfarería analizado en este trabajo. Los estudios distribucionales efectuados en los sitios donde se recuperaron los apéndices analizados, indican que la alfarería zoomorfa se asoció a contextos, tanto domésticos como funerario: un $7 \%$ en asociación directa con enterratorios (como ajuar), un $14 \%$ en probable asociación con enterratorios y un $79 \%$ a espacios domésticos (Ottalagano 2010).

La iconografía Goya-Malabrigo corresponde predominantemente a figuras unitarias de animales. La figura humana ha sido escasamente representada, generalmente con carácter también unitario (Serrano 1961), y en algunos casos combinada con rasgos ornitomorfos, como sucede en el sitio La Palmera 2 (Ceruti 2018). En un trabajo previo se discutió cómo la iconografía zoomorfa se relacionó con cuestiones de identidad, en el marco de procesos de complejidad (Ottalagano 2010, 2013). La presencia de regularidades en lo artístico (p.ej., referidas a la morfología, estructura y gestos tecnológicos) fueron entendidas como parte de un estilo emblemático (sensu Wiessner 1983), destinado a transmitir mensajes precisos con respecto a la identidad grupal. El desempeño de lo artístico en distintos ámbitos de funcionamiento habría permitido naturalizar el simbolismo de tal diferenciación social, ya que las distinciones que marcan límites culturales se legitiman en su continua repetición en la vida diaria (Hodder 1982a, 1982b). Estas sociedades de pequeña escala habrían estado inmersas en procesos de intensificación en la explotación del ambiente, defensa activa del territorio y surgimiento de jerarquías sociales (Bonomo et al. 2011; Ceruti 2018; Loponte y Acosta 2016a; Ottalagano 2013). En este marco, la proyección de una identidad grupal a través de pautas estilísticas distintivas, en artefactos sujetos a un alto nivel de exposición, habría sido una conducta apropiada a fin de señalar límites que permitan excluir a otras poblaciones del acceso a recursos clave y/o establecer relaciones de alianza en situaciones de conflicto. La expresión cotidiana de símbolos de identidad podría entenderse, entonces, como un correlato arqueológico de interacciones sociales de alianza y conflicto (Ottalagano 2010, 2013).

\section{Materiales y Métodos}

Se analizaron 191 figuras zoomorfas en cerámica, muchas de las cuales son inéditas y/o carecen de precisiones taxonómicas. La mayor parte de la muestra analizada fue recuperada en los siguientes sitios arqueológicos: Puerto Cuartel 1 (PC1), Arroyo 
Las Mulas 1 (ALM1), Arroyo Arenal 1 y 4 (AA1 y AA4), Arroyo Largo 1 y 5 (AL1 y AL5), La Palmera 2 (LP2) y Cerro Puesto Acosta (CPA), localizados al este de provincia de Entre Ríos, sobre la margen izquierda del Río Paraná (Figura 1). Constituyen sitios multipropósito, cuya cronología asociada oscila entre $\operatorname{los} 488 \pm 24$ y los $1056 \pm 47{ }^{14} \mathrm{C}$ años AP. La mayor parte de las piezas $(n=138)$ proviene de trabajos de excavación efectuados por Serrano (1946), Ceruti $(1989,2003)$ y por la autora de este trabajo (Ottalagano 2016; Ottalagano et al. 2010, 2015); y proceden tanto de contextos domésticos como funerarios (Ceruti 2018; Ottalagano 2013) (ver apartado previo). Las 53 piezas restantes fueron recolectadas por privados en los sitios ALM1 y AL1, o bien en ubicaciones por el momento inespecíficas dentro del área de estudio. Los apéndices analizados forman parte de las colecciones del Museo Regional
"Alicia González Castrillón" (La Paz, provincia de Entre Ríos) y del Museo de Ciencias Naturales y Antropológicas "Prof. Antonio Serrano" (ciudad de Paraná, provincia de Entre Ríos). En la Tabla 1 se resume la información mencionada.

Las piezas analizadas se seleccionaron en función de su integridad y de su realismo o naturalismo. El concepto de naturalismo es empleado aquí, siguiendo a Criado Boado y Penedo Romero (1989), para describir la capacidad de representar de forma fidedigna la naturaleza. Fueron descartadas de este estudio aquellas figuras con muy bajo nivel de naturalismo (estilizadas) $(\mathrm{n}=19)$, en las que no se pudo observar el rasgo básico para poder atribuirlas a un macro taxón, como por ejemplo: el pico en el caso de las aves, y las orejas y el hocico en el caso de los mamíferos (Tabla 2). De igual manera, se excluyeron aquellos apéndices con baja integridad $(n=15)$, en los que la alta fragmentación impidió registrar

Tabla 1. Procedencia y cronología asociada de las piezas analizadas.

Origins of the pieces analyzed and their associated chronology.

\begin{tabular}{|c|c|c|c|c|}
\hline & Procedencia & $\mathrm{N}$ & $\begin{array}{c}\text { Cronología } \\
\left({ }^{14} \mathrm{C} \text { años AP }\right)\end{array}$ & Fuente \\
\hline \multirow{10}{*}{$\begin{array}{l}\text { Sitio } \\
\text { arqueológico/ } \\
\text { ubicación } \\
\text { aproximada }\end{array}$} & Puerto Cuartel 1 & 6 & & Ceruti 1989 \\
\hline & Arroyo Arenal 1 & 16 & $\begin{array}{l}488 \pm 24^{(\mathrm{a})} \\
625 \pm 46^{\text {(b) }}\end{array}$ & $\begin{array}{l}\text { Ceruti 1989; } \\
\text { Ottalagano } 2016\end{array}$ \\
\hline & Arroyo Arenal 4 & 2 & & Ceruti et al. 1980 \\
\hline & Arroyo Las Mulas 1 & 66 & $\begin{array}{l}750 \pm 50^{(\mathrm{c})} \\
950 \pm 120^{(\mathrm{d})}\end{array}$ & $\begin{array}{l}\text { Ceruti } 1989 ; \\
\text { Serrano } 1946 ; \\
\text { Ottalagano este trabajo }\end{array}$ \\
\hline & Arroyo Largo 1 & 30 & $\begin{array}{r}900 \pm 120^{(\mathrm{e})} \\
1380 \pm 100^{(\mathrm{f})}\end{array}$ & Ceruti 1989 \\
\hline & Arroyo Largo 5 & 2 & & Ceruti 1989 \\
\hline & La Palmera 2 & 16 & $\begin{array}{l}1032 \pm 47^{(\mathrm{g})} \\
1056 \pm 47^{(\mathrm{h})}\end{array}$ & $\begin{array}{l}\text { Ceruti } 1989 \text { Ottalagano } \\
\text { et al. } 2015\end{array}$ \\
\hline & Cerro Puesto Acosta & 1 & & Ottalagano et al. 2010 \\
\hline & Cercanías de ciudad de La Paz (Paraná medio), sin determinar & 45 & & \\
\hline & Cuenca del Paraná medio o inferior, sin determinar & 7 & & \\
\hline \multirow{6}{*}{$\begin{array}{l}\text { Investigador/ } \\
\text { colección }\end{array}$} & Colección C. Ceruti, Museo "Prof. A. Serrano" & 91 & & \\
\hline & Colección A. Serrano, Museo "Prof. A. Serrano" & 21 & & \\
\hline & Colección Museo "Prof. A. Serrano" & 11 & & \\
\hline & Colección Museo "A. González Castrillón" & 20 & & \\
\hline & Colección privada V. Flores & 33 & & \\
\hline & Excavaciones autora & 15 & & \\
\hline
\end{tabular}

(a) y (b) Ottalagano (2016); (c) Cornero y Green (2017); (d), (e) y (f) Ceruti (2003); (g) y (h) Ottalagano et al. (2015). 
estos atributos básicos para su identificación. Tampoco se incorporaron aquellas figuras mixtas, atribuibles a seres que combinan características animales y humanas $(\mathrm{n}=2)$. Los apéndices se encuentran fracturados generalmente a la altura del cuello, motivo por el cual en la mayoría de los casos resulta inasequible relevar aspectos de la forma y dimensión de las vasijas que formaron parte. Sobre la base solamente de aquellos que todavía conservaban parte del artefacto cerámico, se pudo determinar su pertenencia a: vasijas abiertas $(n=6)$, vasijas cerradas $(n=4)$ y a campanas $(n=6)$, éstas últimas tanto de tamaño normal $(n=4)$ como en miniatura $(\mathrm{n}=2)$. Un solo apéndice corresponde a un colgante.

Cada una de las figuras zoomorfas fue relevada fotográficamente por la autora desde distintos planos: derecho, izquierdo, superior, inferior, anverso y reverso. Se realizó una comparación exhaustiva y metódica entre los animales representados en la cerámica y la fauna propia del área de estudio, sustentándose para ello en la consulta bibliográfica y en numerosas imágenes (p.ej., Chebez 1994; De la Peña 2019; Iriondo et al. 2007; Narosky y Yzurieta 2004; Olenik y Gavensky 2017; Pereira et al. 2005; Terres 1991; entre otros). Se procedió a identificar la iconografía zoomorfa con el mayor grado de precisión taxonómica posible, en función de criterios anatómicos definidos en trabajos previos para las aves psitaciformes (Ottalagano 2008), así como en base a otros elementos diagnósticos propuestos en este trabajo (Tabla 2), elaborados a partir de la observación de la muestra y de la biografía zoológica consultada

Tabla 2. Taxones identificados en la iconografía y sus elementos diagnósticos reconocibles.

Taxa identified in the iconography and its recognizable diagnostic elements.

\begin{tabular}{|c|c|}
\hline Animal representado & Elementos morfológicos diagnósticos \\
\hline Aves & Presencia de pico. \\
\hline Pisttacidae (p.ej., loros, cotorras) & $\begin{array}{l}\text { Pico robusto en forma de garfio. La mandíbula superior sobresale por sobre la inferior formando } \\
\text { una curva pronunciada. Mandíbula inferior presenta una curva suave. }\end{array}$ \\
\hline Ara (guacamayos) & $\begin{array}{l}\text { Mismos atributos aplicables a Pisttacidae, con demarcación de un sector triangular alrededor de } \\
\text { los ojos. La mandíbula superior tiende a sobresalir excesivamente por sobre la mandíbula inferior. }\end{array}$ \\
\hline Falconidae (rapaces diurnas) & $\begin{array}{l}\text { Pico robusto en forma de garfio. La curvatura de la mandíbula superior es menos pronunciada } \\
\text { que en Pisttacidae. La mandíbula inferior tiende a ser recta. }\end{array}$ \\
\hline Buteogallus coronatus (águila coronada) & Mismos atributos aplicables a Falconidae, con la presencia de un copete nucal. \\
\hline Anatidae (p.ej., patos) & Pico ancho, largo y chato. \\
\hline Chauna torquata (chajá) & Pico pequeño y afilado. Cabeza redondeada con cresta. \\
\hline Asio clamator (lechuzón orejudo) & $\begin{array}{l}\text { Disco facial pronunciado. Pico pequeño en forma de garfio. Ojos grandes. Penachos de } \\
\text { plumas que recubren los oídos. }\end{array}$ \\
\hline Mammalia & Presencia de orejas y hocico. \\
\hline Canidae (p.ej., zorros, perros, lobos) & $\begin{array}{l}\text { Hocico aguzado. La boca tiende a estar ligeramente abierta, distinguiéndose dientes } \\
\text { representados por trazos incisos. }\end{array}$ \\
\hline Felidae (jaguar, pumas, gatos silvestres) & $\begin{array}{l}\text { Hocico romo y poco prominente. La boca tiende a estar ligeramente abierta, en la que pueden } \\
\text { detectarse dientes representados por trazos incisos. Orejas cortas, redondeadas o triangulares. }\end{array}$ \\
\hline Panthera onca (jaguar o yaguareté) & Atributos aplicables a Felidae, con manchas ovaladas en la piel del cuerpo. Orejas redondeadas. \\
\hline Leopardus geoffroyi (gato montés) & Atributos aplicables a Felidae, con manchas punteadas en la piel del cuerpo. Orejas triangulares. \\
\hline $\begin{array}{l}\text { Myrmecophagidae (oso hormiguero y } \\
\text { oso melero) }\end{array}$ & $\begin{array}{l}\text { Cabeza y hocico forman una unidad extremadamente alargada y tubular, que suele estar } \\
\text { inclinada hacia abajo. Orejas y/o ojos pequeños ubicados a los costados de la cabeza. }\end{array}$ \\
\hline Hydrochoerus hydrochaeris (carpincho) & $\begin{array}{l}\text { Hocico muy voluminoso, romo, rectangular y generalmente con una suave curva convexa en su } \\
\text { parte superior. Orejas pequeñas, las cuales pueden estar representadas por una sola protuberancia. }\end{array}$ \\
\hline Lontra longicaudis (lobito de río) & Cabeza alargada. Orejas muy pequeñas, redondeadas, ubicadas hacia atrás y muy separadas entre sí. \\
\hline Serpentes (p.ej., culebra, serpiente) & Cuerpo entero sin extremidades, enroscado u ondulante que finaliza en una cabeza. \\
\hline Viperidae (serpiente) & Atributos aplicables a Serpentes, donde se distingue una cabeza más ancha y triangular. \\
\hline Testudines (tortuga) & Cuerpo entero con caparazón. \\
\hline
\end{tabular}


(ver arriba). Todos aquellos taxones registrados en los conjuntos arqueofaunísticos regionales, fueron especialmente considerados para detectar potenciales concordancias con los animales representados en la cerámica. Igualmente, con la finalidad de registrar eventuales correspondencias, se tuvieron en cuenta también aquellas especies mencionadas en relatos míticos regionales (Mashnshnek 1975; Métraux 1935, 1941; Terán 1985, 1998, ver una síntesis en Ottalagano 2007; entre otros).

La determinación taxonómica de la iconografía zoomorfa es un proceso complejo, ya que existen una serie de limitantes a tener en cuenta, como por ejemplo el nivel de fragmentación del apéndice, su grado de naturalismo y la representación sectorizada de una parte del cuerpo del animal. En tal sentido, solo en un 7,3\% $(n=14)$ de las figuras se diseñó el cuerpo completo del animal, en tanto que en el $92,7 \%(\mathrm{n}=177)$ restante se representó únicamente su cabeza, lo que restringe la identificación a los rasgos presentes exclusivamente en este sector corporal. Para facilitar el reconocimiento zoológico, y a fin de realizar un listado de rasgos diagnósticos para cada taxón, se examinó en detalle la morfología de los distintos atributos de las figuras, como: orejas, hocico o pico, ojos, cuerpo y extremidades (estos últimos en el caso de corresponder).

Los datos zooarqueológicos se analizaron fundamentalmente a partir de la información relevada en aquellos sitios arqueológicos donde se recuperó la mayor parte de los apéndices cerámicos comprendidos en este estudio, y en los cuales la cuantificación faunística se efectuó mediante índices de abundancia taxonómica generales como NISP y MNI (Ottalagano 2016, 2019a; Ottalagano et al. 2015). También se consideró los datos de presencia/ ausencia de especies mencionados por Tonni et al. (1985) para el sitio AA1. Asimismo, se tuvo en cuenta la información referida a la explotación de la fauna, la cual se basó en el análisis de los índices de abundancia de partes esqueletarias (MNE, MAU), así como también en el tipo y ubicación de las marcas antrópicas. Estos datos están disponibles por el momento para el sitio ALM1 (Ottalagano 2019a). Se consideró aquí que la representación esqueletaria diferencial, centrada particularmente en el registro de falanges y metapodios, es particularmente indicadora de actividades de cuereado, ya que estos elementos permanecen generalmente unidos a la piel sin procesar. Este patrón diverge de aquel relacionado con las actividades de procesamiento para el consumo de la carne, las cuales tienden a generar modificaciones en aquellos elementos con alto rendimiento económico, como por ejemplo en los huesos largos (Binford 1981; Lyman 1994; Marean y Cleghorn 2003). Subsidiariamente se discutieron, además, los datos arqueofaunísticos disponibles para otros sitios arqueológicos de la cuenca del Paraná, asociados igualmente a ocupaciones Goya-Malabrigo, donde se registran apéndices zoomorfos.

\section{Las Formas Zoológicas del Arte Cerámico}

Se identificaron tres macro taxones en la muestra: Aves, Mammalia y Reptilia (Tabla 3). No se registraron representaciones atribuibles a Peces ni a Amphibia en las colecciones cerámicas consideradas en este trabajo, como es usual en el registro arqueológico prehispánico de las tierras bajas del Río Paraná, según lo relevado por varios autores (Badano 1946; Ceruti 2017; Gaspary 1950; González 1977, Outes 1918; Serrano 1946, 1961, 1972, entre otros). Al respecto, cabe realizar algunas consideraciones en referencia a un trabajo reciente, en el cual se postula la existencia de figuras duales loros-peces en la cerámica Goya-Malabrigo (Cornero 2018). La propuesta de Cornero (2018) se sustenta en el hallazgo de un apéndice parcialmente fragmentado, donde se observa sutilmente una figura de pez sobre la cabeza de un ave psitaciforme, de modo tal que se fusionan ambas morfologías. El ojo del ave sería al mismo tiempo el ojo del pez. Si bien se menciona que este apéndice procede de una colección privada y se aloja en el Museo Parroquial de San Javier (provincia de Santa Fe), no se aportan detalles del sitio arqueológico donde se recuperó. Este es un punto crucial a tener en cuenta, dado que al no conocerse la información arqueológica contextual del apéndice, es discutible su asociación con un contexto prehispánico. Las pocas representaciones de peces conocidas para la cuenca del Río Paraná provienen del sitio Santa Fe La Vieja (provincia de Santa $\mathrm{Fe}$ ), el cual constituye el primer asiento que tuvo la actual ciudad de Santa Fe entre finales del siglo XVI y mediados del siglo XVII. En este emplazamiento convergieron grupos humanos diversos, originando una sociedad multicultural y multiétnica. Las excavaciones realizadas a finales de 1940 por Zapata Gollán, se efectuaron sin control estratigráfico, por lo que la cronología específica del material hallado en el sitio plantea serias dificultades. Se trata de un sitio cultural y temporalmente complejo, donde es probable que buena parte de la cerámica 
indígena recuperada se vincule con un periodo hispano-indígena (ver discusión en Ceruti 2006). Por tanto, la figura dual pez-ave presentada por Cornero (2018) debería ser tomada con cautela, ya que podría igualmente asociarse con un contexto post-hispánico.

Este apéndice tan particular, considerado por Cornero (2018:92) como el "ideal de representación", le permite extender el concepto de peces-aves al resto de las figuras ornitomorfas que analiza, utilizando para ello la segmentación de la imagen en dos mitades. La propuesta, si bien contribuye a pensar la posible existencia de figuras duales, no discute adecuadamente aquellos rasgos (incisos y modelados) de las figuras ornitomorfas que atribuye a peces; omitiéndose, además, confrontar la propia interpretación con otras previamente formuladas, en las cuales estos mismos rasgos se consideraron como típicos de aves. Por ejemplo, las protuberancias modeladas y/o incisas que se encuentran en la parte posterior de la cabeza y en la nuca de las figuras ornitomorfas, Cornero (2018) las identifica a priori como aletas, sin profundizar en su morfología, ni realizar una exhaustiva comparación con la anatomía de las aletas de los peces. Como se observa en los ejemplos de psitácidos de la Figura 2, la forma de estas protuberancias difiere de aquella propia de las aletas. Podrían ser entendidas, en cambio, como las plumas encrespadas de los loros, como argumentaron inicialmente autores como González (1977) ${ }^{1}$, y como se ejemplificó en Ottalagano (2013). Cabe destacar, además, que Cornero (2018) incluye en su análisis figuras zoomorfas publicadas por terceros. Esto limita la posibilidad de observarlas desde distintos planos, lo que aportaría a su identificación. Otros de los atributos que considera propio de los peces, son las líneas incisas que demarcan un sector alrededor de los ojos de las figuras, y que interpreta como opérculos de peces (Cornero 2018). Este rasgo, que será retomado en detalle en el apartado siguiente, ha sido mencionado por Ottalagano (2008) como un atributo diagnóstico de las especies del género Ara, como se visualiza en la mayoría de los ornitomorfos de la Figura 2. Por otro lado, la línea incisa que marca la unión entre el maxilar superior e inferior del pico las aves (Figura 2), Cornero (2018:95) las interpreta como "picos dentados". Cabe señalar que los dientes

Tabla 3. Animales representados en la iconografía cerámica por sitio arqueológico.

Representation of animals in ceramic iconography by archaeological site.

\begin{tabular}{|c|c|c|c|c|c|c|c|c|c|c|c|}
\hline \multirow{2}{*}{ Taxón } & \multirow{2}{*}{$\mathrm{PC} 1$} & \multirow{2}{*}{ ALM1 } & \multirow{2}{*}{ AA1 } & \multirow{2}{*}{ AA4 } & \multirow{2}{*}{ AL1 } & \multirow{2}{*}{ AL5 } & \multirow{2}{*}{ LP2 } & \multirow{2}{*}{ CPA } & \multirow{2}{*}{$\mathrm{s} / \mathrm{u}$} & \multicolumn{2}{|c|}{ Total } \\
\hline & & & & & & & & & & $\mathrm{N}$ & $\%$ \\
\hline Aves & & 3 & & & 2 & 1 & 4 & & 9 & 19 & 10 \\
\hline Pisttacidae & 6 & 14 & 9 & 2 & 11 & 1 & 4 & & 25 & 72 & 37,7 \\
\hline Ara & & 25 & 4 & & 10 & & 1 & & 8 & 48 & 25,1 \\
\hline Falconidae & & 1 & & & & & 2 & 1 & & 4 & 2,1 \\
\hline Buteogallus coronatus & & 1 & & & & & & & & 1 & 0,5 \\
\hline Anatidae & & 1 & & & & & 1 & & & 2 & 1 \\
\hline Chauna torquata & & & & & 1 & & & & & 1 & 0,5 \\
\hline Asio clamator & & 1 & & & & & & & & 1 & 0,5 \\
\hline Mammalia & & 5 & & & 4 & & 3 & & 3 & 15 & 7,8 \\
\hline Felidae & & 1 & 1 & & & & 1 & & 4 & 7 & 3,6 \\
\hline Panthera onca & & 1 & & & 1 & & & & & 2 & 1 \\
\hline Leopardus geoffroyi & & 1 & & & & & & & & 1 & 0,5 \\
\hline Canidae & & 1 & & & & & & & & 1 & 0,5 \\
\hline Lontra longicaudis & & 1 & & & & & & & & 1 & 0,5 \\
\hline Hydrochoerus hydrochaeris & & 3 & & & & & & & 2 & 5 & 2,6 \\
\hline Myrmecophagidae & & 1 & & & & & & & 1 & 2 & 1 \\
\hline Reptilia & & & 1 & & & & & & & 1 & 0,5 \\
\hline Serpentes & & 4 & 1 & & 1 & & & & & 6 & 3,1 \\
\hline Viperidae & & 1 & & & & & & & & 1 & 0,5 \\
\hline Testudines & & 1 & & & & & & & & 1 & 0,5 \\
\hline Total Aves & 6 & 46 & 13 & 2 & 24 & 2 & 12 & 1 & 42 & 148 & 77,5 \\
\hline Total Mammalia & & 14 & 1 & & 5 & & 4 & & 10 & 34 & 17,8 \\
\hline Total Reptilia & & 6 & 2 & & 1 & & & & & 9 & 4,7 \\
\hline
\end{tabular}

Los valores expresan la cantidad de figuras zoomorfas; s/u = sin ubicación precisa. 
no son una característica exclusiva de los peces, y que además, parte de la ictiofauna del Paraná carece de dientes. Tal es el caso de sábalos, bagres y armados, los cuales han formado parte de la dieta prehispánica de estos grupos (ver apartado anterior). En un trabajo coetáneo, publicado por Píccoli y Barboza (2018:54), se encuentra igualmente presente la idea de figuras duales peces-aves. Las autoras afirman que en la colección analizada (procedente de las provincias de Corrientes y Santa Fe), “...casi en su totalidad refiere a modelados zoomorfos que clasifica en relación a distintos taxa correspondientes a aves y peces". Sin embargo, no se especifican los criterios empleados para elaborar esta afirmación, y tampoco se aportan imágenes que permitan observar tal identificación.

\section{Las aves en la iconografía}

Dentro de la Clase Aves se agrupa la mayor parte de las figuras zoomorfas analizadas (Tabla 3). El pico, que es una morfología particular del maxilar superior e inferior revestida por una capa córnea, constituye el elemento diagnóstico mínimo para reconocer en el registro artístico a este macro taxón. En algunos casos aparecen también otros rasgos secundarios asociados, como plumas nucales, plumas caudales

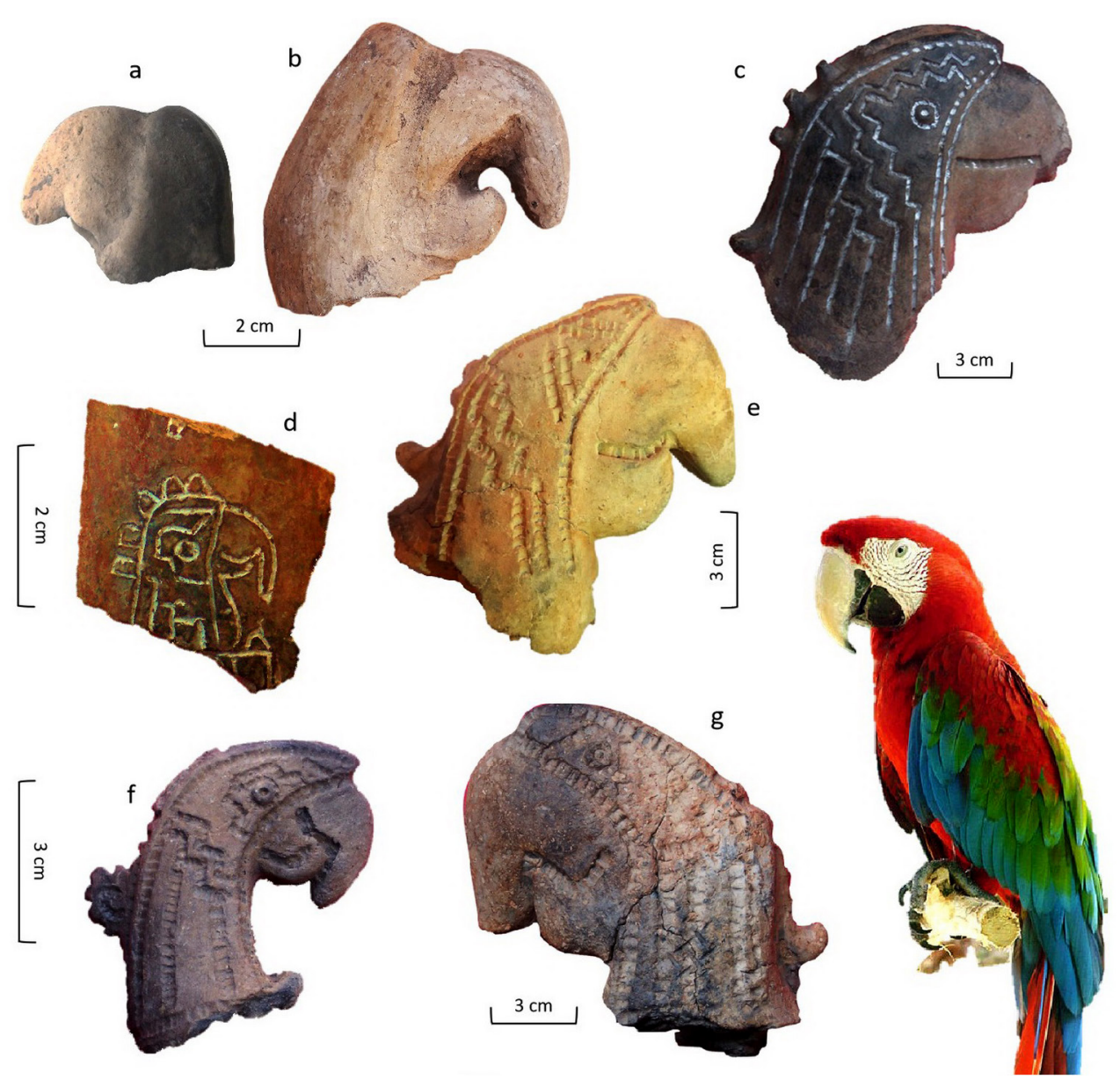

Figura 2. Representaciones de aves psittaciformes: (a) y (b) Psittacidae del sitio AA1 (excavación autora); (c) Ara del sitio ALM1 (Museo Serrano); (d) Ara del sitio ALM1 (colección Ceruti, Museo Serrano); (e) Ara del sitio AL1 (Museo González Castrillón); (f) Ara del sitio ALM1 (colección Ceruti, Museo Serrano); (g) Ara del sitio AL1 (colección Ceruti, Museo Serrano), derecha: ejemplar de Ara chloroptera. La pintura blanca en (c) y (d) no es original.

Representations of psittaciformes birds: (a) and (b) Psittacidae from AA1 site (author's excavation); (c) Ara from ALM1 site (Serrano Museum); (d) Ara from ALM1 site (Ceruti collection, Serrano Museum); (e) Ara from AL1 site (González Castrillón Museum); (f) Ara from ALM1 site(Ceruti collection, Serrano Museum); ( $g$ ) Ara from AL1 site (Ceruti collection, Serrano Museum), right: Ara chloroptera specimen. The white paint on pieces $(c)$ and $(d)$ is not original. 
y alas, especialmente en aquellas figuras donde el animal se representa a cuerpo completo, como en los artefactos "campana".

La morfología de los picos de las aves guarda una estrecha relación con la manera en que éstas obtienen y procesan su alimento (Terres 1991), por lo que constituye también un indicador taxonómico. Los picos robustos en forma de garfio, claramente atribuibles a la Familia Psittacidae, resultan ampliamente predominantes, registrándose en un total de 120 piezas con distingo grado de naturalismo y estilización (Tablas 2 y 3, Figura 2). Como ha sido analizado en Ottalagano (2008), en varias representaciones de Psittacidae se realizaron trazos incisos que demarcan un área triangular alrededor de los ojos, la cual puede ser considerada como el correlato de la zona facial carente de plumas que caracteriza al género Ara (guacamayos) ${ }^{2}$. En las especies de este género, los picos suelen ser, asimismo, mucho más voluminosos en comparación con las otras especies de psitácidos del área, como el loro barranquero del sur (Cyanoliseus patagonus) o la cotorra común
(Myiopsitta monachus). El guacamayo rojo (Ara chloroptera), por ejemplo, cuya distribución se extendía por el corredor paranaense hasta la provincia de Corrientes (Chebez 1994), presenta caracteres morfológicos muy similares a aquellos encontrados en buena parte de la iconografía, tal como se observa en la Figura 2.

En la muestra se distinguen también picos robustos en forma de garfio, pero con una curva menos pronunciada que aquella propia de la Familia Psittacidae. Éstos son típicos de las rapaces diurnas, como la Familia Falconidae (Tablas 2 y 3, Figura 3) que incluye especies como el carancho (Caracara plancus), el chimango (Phalcoboenus chimango) y los halcones (p.ej., Falco femoralis). Dentro de este grupo se logró identificar al águila coronada (Buteogallus coronatus) en el sitio ALM1, a partir de su característico copete nucal (Figura 3a). Para este mismo sitio, Serrano (1946:84) publica otro apéndice falconiforme que considera una representación de un águila gris de copete, probablemente haciendo referencia también a $B$. coronatus.

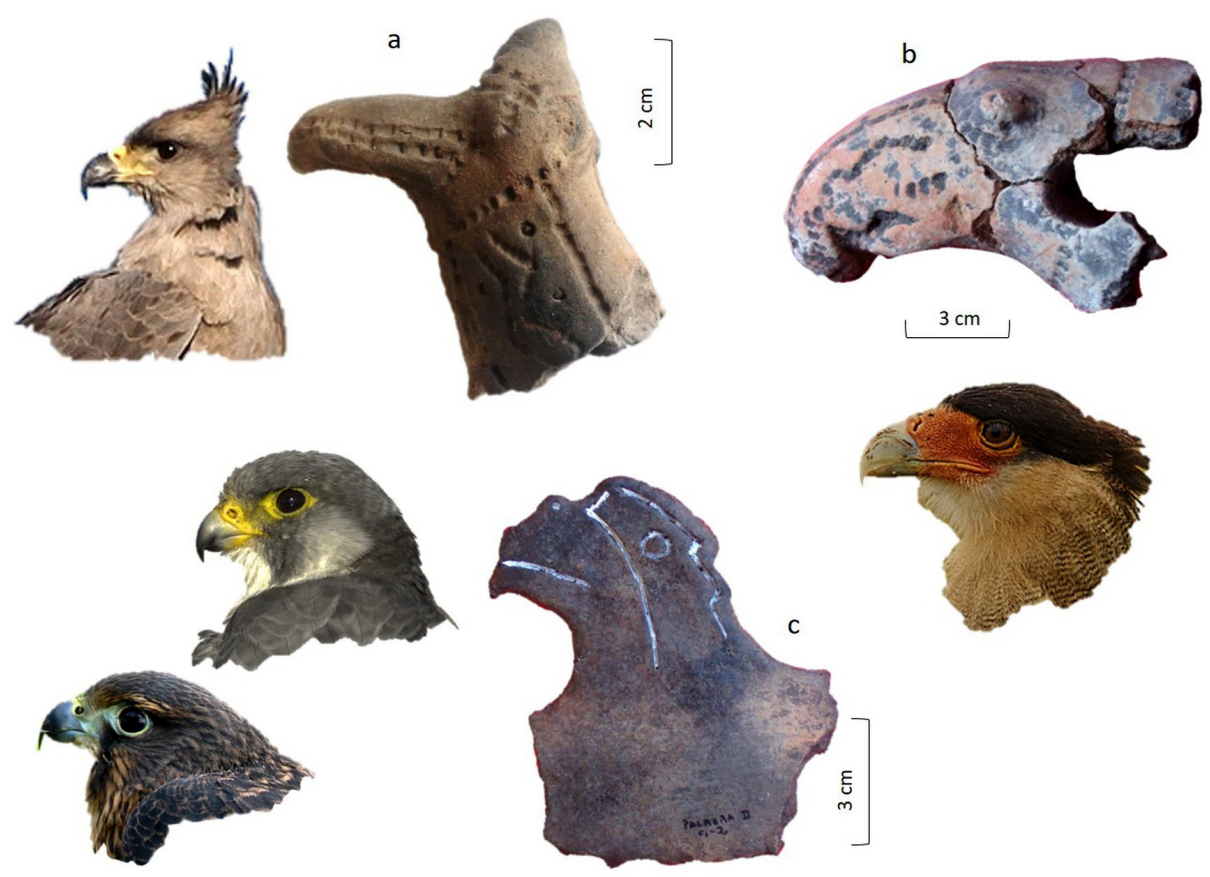

Figura 3. Representaciones de aves falconiformes: (a) Buteogallus coronatus del sitio ALM1 (excavación autora) (foto de B. coronatus: Fernando Bernasconi); (b) Falconidae del sitio CPA (excavación autora), abajo: ejemplar de Caracara plancus; (c) Falconidae del sitio LP2 (colección Ceruti, Museo Serrano), izquierda: ejemplares de Falco peregrinus y F. femoralis. La pintura blanca en (c) no es original.

Representations of falconiformes birds: (a) Buteogallus coronatus from ALM1 site (author excavation) (B. coronatus photo: Fernando Bernasconi); (b) Falconidae from CPA site (author excavation), below: Caracara plancus specimen; (c) Falconidae from LP2 site (Ceruti collection, Serrano Museum), left: Falco peregrinus and $\mathrm{F}$. femoralis specimens. The white paint in $(c)$ is not original. 
No se reconocieron ejemplares de Cathartidae, como los registrados por Cornero (2019) en apéndices procedentes especialmente de la margen derecha del Paraná. Esta autora interpretó la pieza que se visualiza en la Figura 3c como una representación de cóndor andino (Vultur gryphus) (Cornero 2019:143), sin embargo, no se observa la típica cabeza horizontalmente alargada propia de esta especie alóctona al área de estudio. Esta pieza, que fue primeramente considerada como un ave psitaciforme por Ottalagano (2013), presenta cierto grado de estilización y está elaborada en dos dimensiones (figura recortada, sensu Serrano 1946), hecho que reduce la visibilidad de los atributos diagnósticos. No obstante, teniendo en cuenta las determinaciones especificadas en la Tabla 2, particularmente en relación a la morfología de la mandíbula inferior, podría ser interpretada más bien como un ejemplar de Falconidae, probablemente como un halcón plomizo (Falco femoralis) o un halcón peregrino (F. peregrinus) (Figura 3c).

Dentro de las rapaces nocturnas se pudo reconocer particularmente una representación de lechuzón orejudo (Asio clamator) en el sitio ALM1 (Tablas 2 y 3). Esta pieza fue previamente reconocida como un ñacurutú (Bubo virginianus) por Ceruti (1989), y de hecho ambas especies comparten la presencia de penachos de pluma en la cabeza, por lo que son bastante parecidas. Sin embargo, A. clamator posee un disco facial mucho más marcado, equivalente al observado en la Figura 4a. Para este mismo sitio, Serrano (1946:85) publica una pieza muy similar. Esta es interpretada por el autor como un búho, en tanto que Badano (1946) la identifica como un ejemplar de A. clamator. Es de destacar que en el sitio LP2, Ceruti (2018) recuperó particularmente una representación que combina una boca humana con el característico disco facial propio de estas aves Strigiformes ${ }^{3}$. De acuerdo a Gomes (2019) estas imágenes que presentan características a la vez humanas y animales, en lugar de representar a seres híbridos, podrían pensarse como una manera de materializar la transformación de estados corpóreos, es decir, de expresar un proceso de metamorfosis humano-animal.

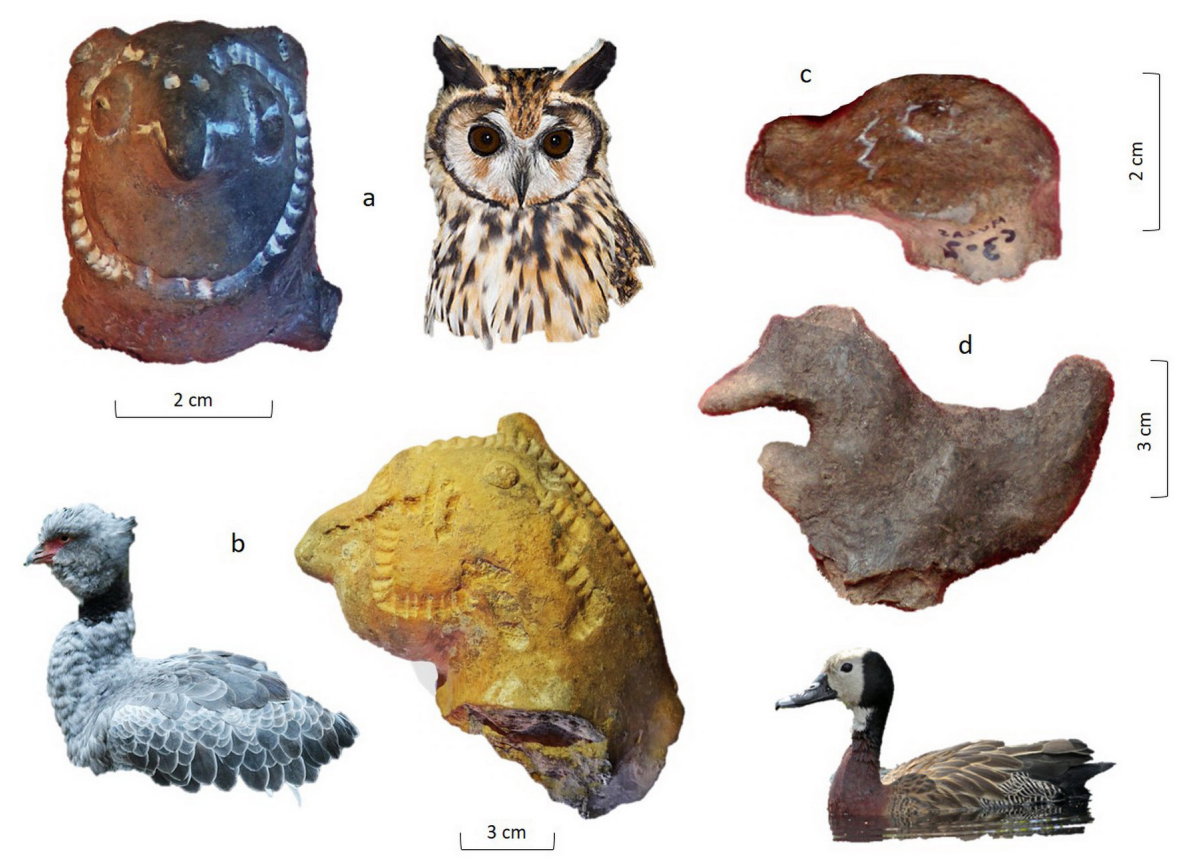

Figura 4. Representaciones de aves strigiformes y anseriformes: (a) Asio clamator del sitio ALM1 (colección Ceruti, Museo Serrano); (b) Chauna torquata del sitio AL1 (Museo González Castrillón); (c) Anatidae del sitio ALM1 (colección Ceruti, Museo Serrano); (d) Anatidae del sitio LP2 (colección Ceruti, Museo Serrano), abajo: ejemplar de Dendrocygna viduata. La pintura blanca en (a) y (c) no es original.

Representations of strigiformes and anseriformes birds: (a) Asio clamator from ALM1 site (Ceruti collection, Serrano Museum); (b) Chauna torquata from AL1 site (González Castrillón Museum); (c) Anatidae from ALM1 site (Ceruti collection, Serrano Museum); (d) Anatidae from LP2 site (Ceruti collection, Serrano Museum), below: Dendrocygna viduata specimen. On pieces $(a)$ and $(c)$, the white paint is not original. 
Se identificaron tres apéndices correspondientes a aves Anseriformes: dos representaciones de patos (Familia Anatidae) y una representación muy realista de chajá (Chauna torquata) (Tablas 2 y 3, Figura 4). Particularmente para el sitio ALM1, Serrano (1946) publicó además cuatro apéndices que no pudieron ser localizados para este trabajo, los cuales interpreta respectivamente como posibles ejemplares de muitú (Crax fasciolata), ñandú (Rhea americana), pirincho negro (Crotophaga ani) y cardenal de copete rojo (Paroaria coronata). En un 12,8\% ( $\mathrm{n}=19)$ de las representaciones de aves analizadas, se observó un pico indefinido debido a la estilización, los cuales no pudieron ser atribuidos con certeza a ningún taxón en particular (Tabla 3).

\section{Los mamíferos en la iconografía}

Los mamíferos se reconocieron en el arte cerámico principalmente por poseer orejas y generalmente un hocico que se proyecta hacia adelante. Las orejas o pabellones auditivos visibles, que constituyen el elemento diagnóstico por excelencia de los mamíferos, a excepción de ciertos mamíferos marinos (Bastida et al. 2007), tienden a presentar en la muestra distinto grado de naturalismo según la especie, como se verá más adelante. Un 29,4\% $(n=10)$ de las representaciones de mamíferos corresponden a ejemplares de la Familia Felidae (Tabla 3), los cuales pueden reconocerse por los atributos detallados en la Tabla 2. Se identificaron dos especies locales: Panthera onca (jaguar) y Leopardus geoffroyi (gato montés) (Figura 5). Ambas presentan manchas oscuras en la piel, pudiendo ser confundidas. Sin embargo, teniendo en cuenta los rasgos presentes solamente en la cabeza del animal, se puede notar diferencias en relación a las orejas de ambos felinos: las de $P$. onca son redondeadas, mientras que las de L. geoffroyi poseen una tendencia triangular. Esta morfología triangular de las orejas también puede ser reconocida en otros felinos locales como Puma concolor y L. colocolo. El jaguar posee además otros rasgos diagnósticos en la zona del cuerpo, que son las
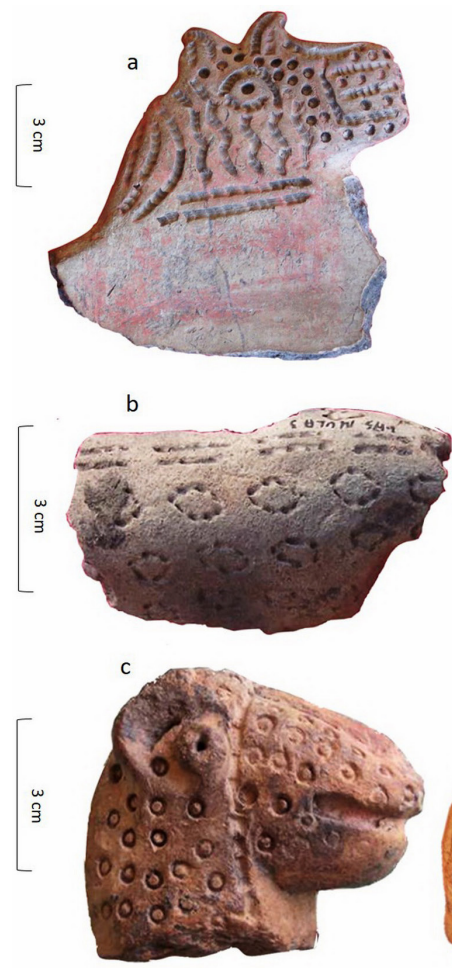
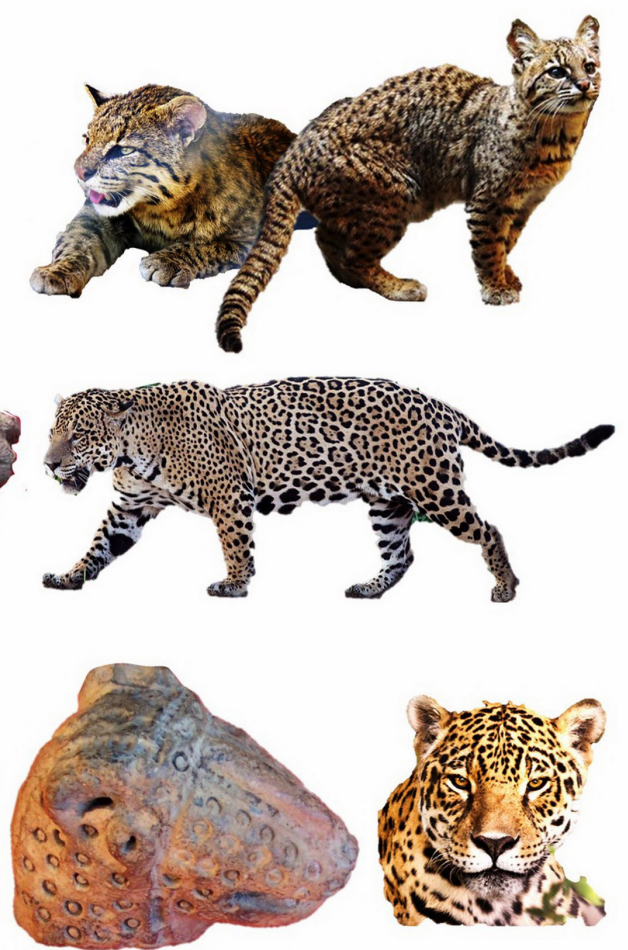

Figura 5. Representaciones de jaguar y gato montés: (a) Leopardus geoffroyi del sitio ALM1 (colección Serrano, Museo Serrano); (b) Panthera onca (apéndice fragmentado) del sitio ALM1 (colección Serrano, Museo Serrano); (c) P. onca del sitio AL1 (Museo Serrano).

Representations of jaguar and Geoffroy's cat: (a) Leopardus geoffroyi from ALM1 site (Serrano collection, Serrano Museum); (b) Panthera onca (fragmented appendage) from ALM1 site (Serrano collection, Serrano Museum); (c) P. onca from AL1 site (Serrano Museum). 
típicas manchas ovaladas. Como puede apreciarse en la Figura 5b, estas manchas se han elaborado en la cerámica mediante incisión. La Figura 6d, posiblemente pueda tratarse de una representación de Herpailurus yagouaroundi syn. Puma yagouaroundi (yaguarundí), ya que este felino se caracteriza por presentar orejas redondeadas y un pelaje liso.

Merece particularmente atención el ejemplar de la Figura 6e, que constituye un ejemplo excepcional donde un mismo apéndice reúne dos modelados de especies diferentes. Fue publicada originalmente por Serrano (1972:43), sin realizar precisiones taxonómicas. En esta pieza se distingue una gran cabeza de guacamayo, sobre la cual se ubica un felino proporcionalmente más pequeño. Sumado a los rasgos diagnósticos indicados en la Tabla 2, aquí debe considerarse también la posición de las patas traseras del animal que reposa sobre sus dedos sin apoyar la articulación del talón (digitígrado), que es una característica típica en felinos y que está presente en este ejemplar. Sus orejas redondeadas y su cuerpo decorado con incisiones, podrían indicar que se trata de un jaguar; no obstante lo cual, no se identifican las típicas manchas ovaladas en el cuerpo, por lo que no puede ser asignado con certeza a esta especie. El cuerpo voluminoso de este motivo zoomorfo podría sugerir asimismo la representación de una hembra en estado de gestación.

El carpincho (Hydrochoerus hydrochaeris) constituye otro de los mamíferos que se encuentra representado en varias piezas, provenientes en su mayoría del sitio ALM1 (Tabla 3). El hocico romo, rectangular, muy voluminoso y generalmente con una suave curva convexa en su parte superior, es determinante para el reconocimiento de esta especie (Tabla 2, Figura 7). Las orejas de este gran roedor son pequeñas, y se encuentran representadas mediante una única protuberancia, como si se tratara de una figura bidimensional vista de perfil. Solo en la Figura 7c, cada una de las orejas ha sido levemente insinuada mediante modelado, pero en ningún caso aparecen como un rasgo acentuado, como ocurre en las otras especies identificadas. A diferencia de los felinos que presentan mayor naturalismo, el carpincho fue representado de manera más estilizada. En varios casos se omitió el diseño de los ojos y de las fosas nasales, por ejemplo.
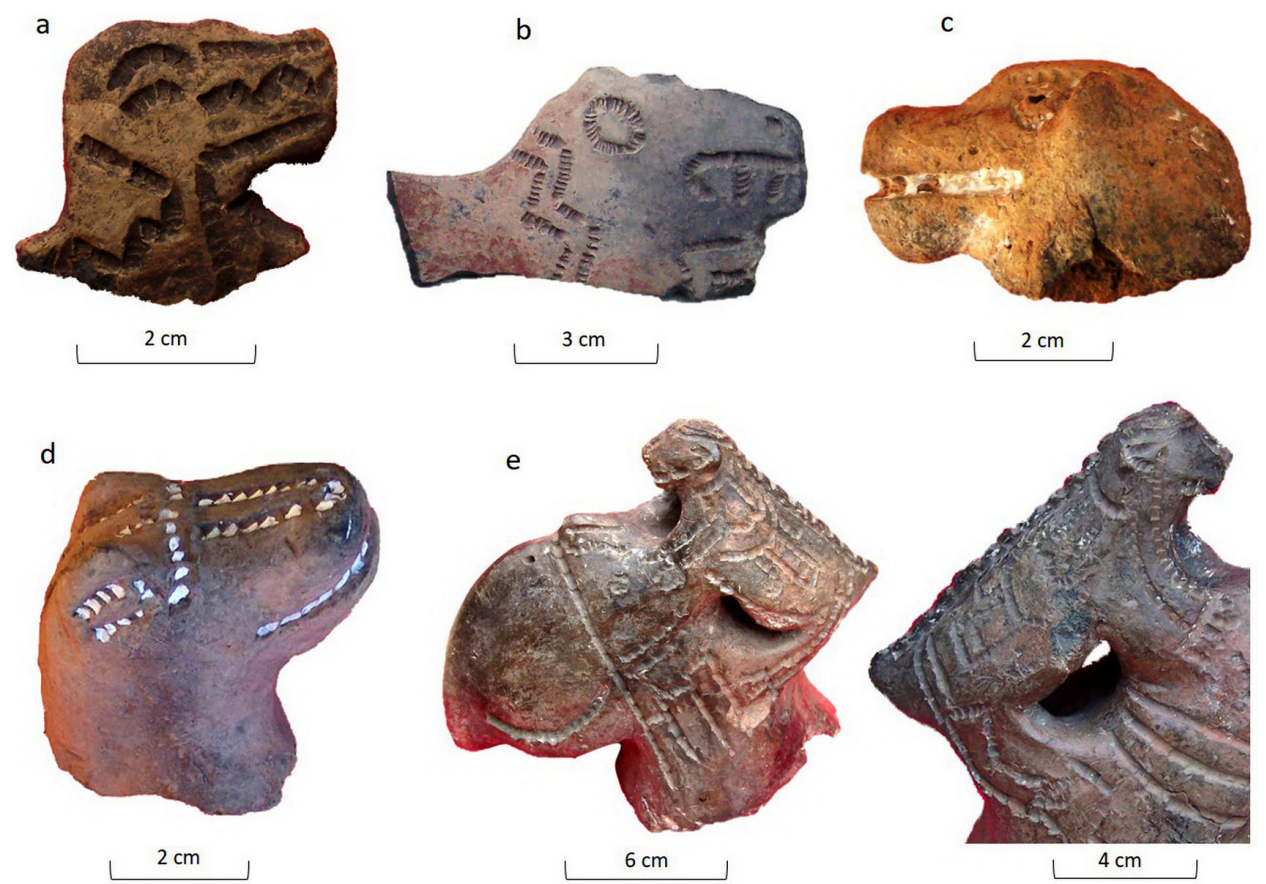

Figura 6. Representaciones de felinos indeterminados: (a) sitio LP2 (colección Ceruti); (b) y (c) cuenca del Paraná (Museo Serrano); (d) sitio AA1 (colección Ceruti); (e) sitio ALM1 (colección Serrano, Museo Serrano). La pintura blanca en (c) y (d) no es original.

Indeterminate feline representations: (a) LP2 site (Ceruti collection); (b) and (c) Paraná basin (Serrano Museum); (d) AA1 site (Ceruti collection); (e) ALM1 site (Serrano collection, Serrano Museum). On pieces (c) and (d), the white paint is not original. 

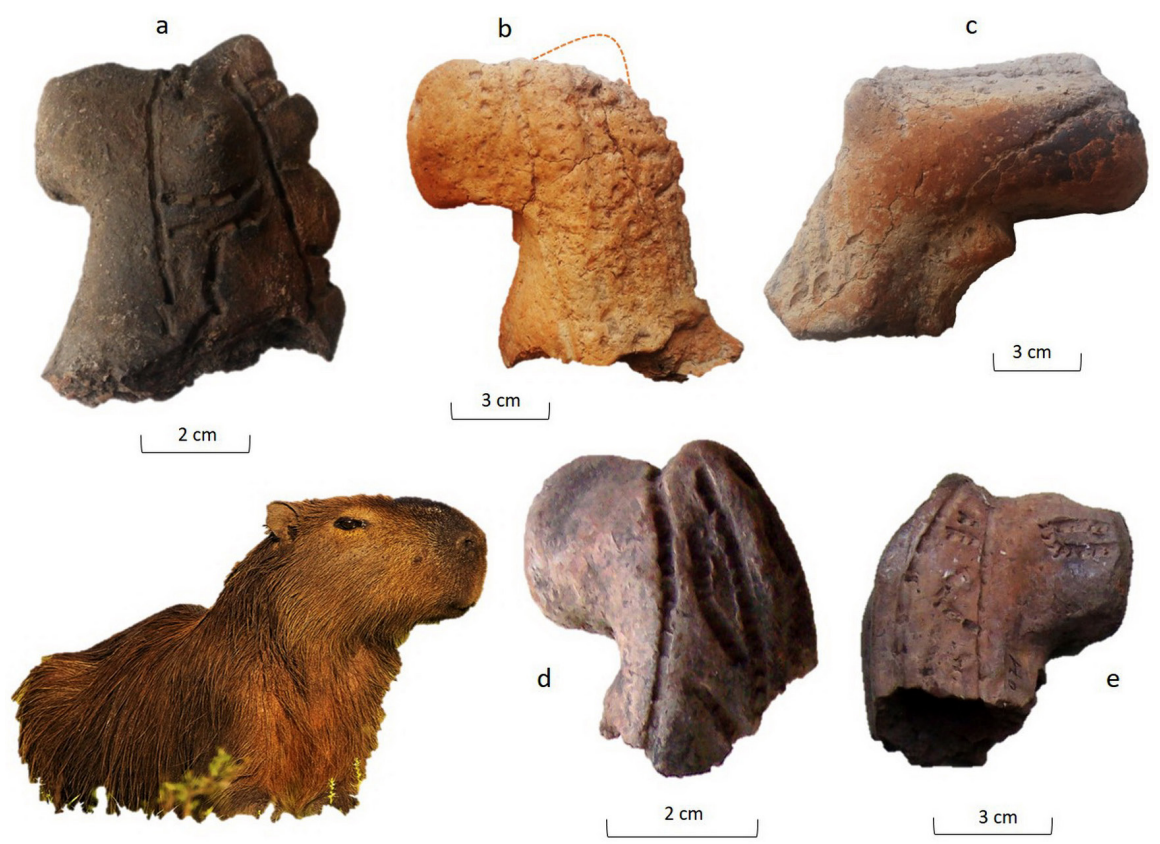

Figura 7. Representaciones de Hydrochoerus hydrochaeris: (a) sitio ALM1 (excavación autora); (b) y (c) Paraná medio (colección privada); (d) y (e) sitio ALM1 (Museo Serrano, respectivamente colección Ceruti y Serrano).

Hydrochoerus hydrochaeris representations: (a) ALM1 site (author excavation); (b) and (c) Middle Paraná (private collection); (d) and (e) ALM1 site (Serrano Museum, Ceruti and Serrano collection).

Dos piezas pueden ser adjudicadas a ejemplares de la Familia Myrmecophagidae (Tablas 2 y 3, Figura 8). El ejemplar de la Figura 8a fue particularmente identificado previamente por Ceruti (1989) como un Tamandua tetradactyla (oso melero), aunque también podría representar a un ejemplar de Myrmecophaga tridactyla (oso hormiguero gigante), de distribución algo más septentrional que la especie anterior, y cuya cabeza extremadamente alargada y tubular es muy similar. De estas dos piezas, la Figura 8a está efectuada con gran naturalismo, mientras que aquella de la Figura 8b, posee mayor grado de estilización, distinguiéndose pequeñas orejas, pero omitiéndose los ojos.

La pieza que se observa en la Figura 8 c constituye un ejemplar de Lontra longicaudis (lobito de río), reconocido previamente como tal por Ceruti (1980). Los rasgos diagnósticos de esta especie se ejecutaron con gran naturalismo en esta pieza (Tabla 2). El ejemplar de la Figura 8d puede considerarse un cánido, debido al hocico aguzado que presenta, que es una característica de zorros (p.ej., zorro gris pampeano, Lycalopex gymnocercus), perros prehispánicos (Canis familiaris) y del lobo de crin o aguará guazú (Chrysocyon brachyurus $)^{4}$. Si bien está realizada igualmente con gran naturalismo, la fragmentación del apéndice impide observar otros rasgos, como por ejemplo las orejas, generalmente prominentes entre los ejemplares de Canidae. La representación de la boca sugiere que se encuentra ligeramente abierta, distinguiéndose grandes colmillos superiores realizados mediante incisión. Finalmente, 15 figuras de la muestra analizada se clasificaron como Mammalia (Tabla 3), sin poder asignarse a un nivel taxonómico más preciso. Cabe señalar que 12 de las mismas constituyen fragmentos mínimos del apéndice original, en los cuales gran parte de la cabeza del animal está truncada, impidiendo el reconocimiento de mayores detalles taxonómicos. Solo tres apéndices correspondientes a mamíferos fuero realizados con bajo grado de naturalismo, limitando igualmente una determinación más precisa.

En el sitio ALM1, Serrano (1946) publica además otras piezas zoomorfas que no pudieron ser localizadas para este estudio, las cuales este autor identifica como un mono carayá (Alouatta caraya), un pecarí (Tayassu pecari), un lobito de río (L. longicaudis), un puma (Puma concolor) 

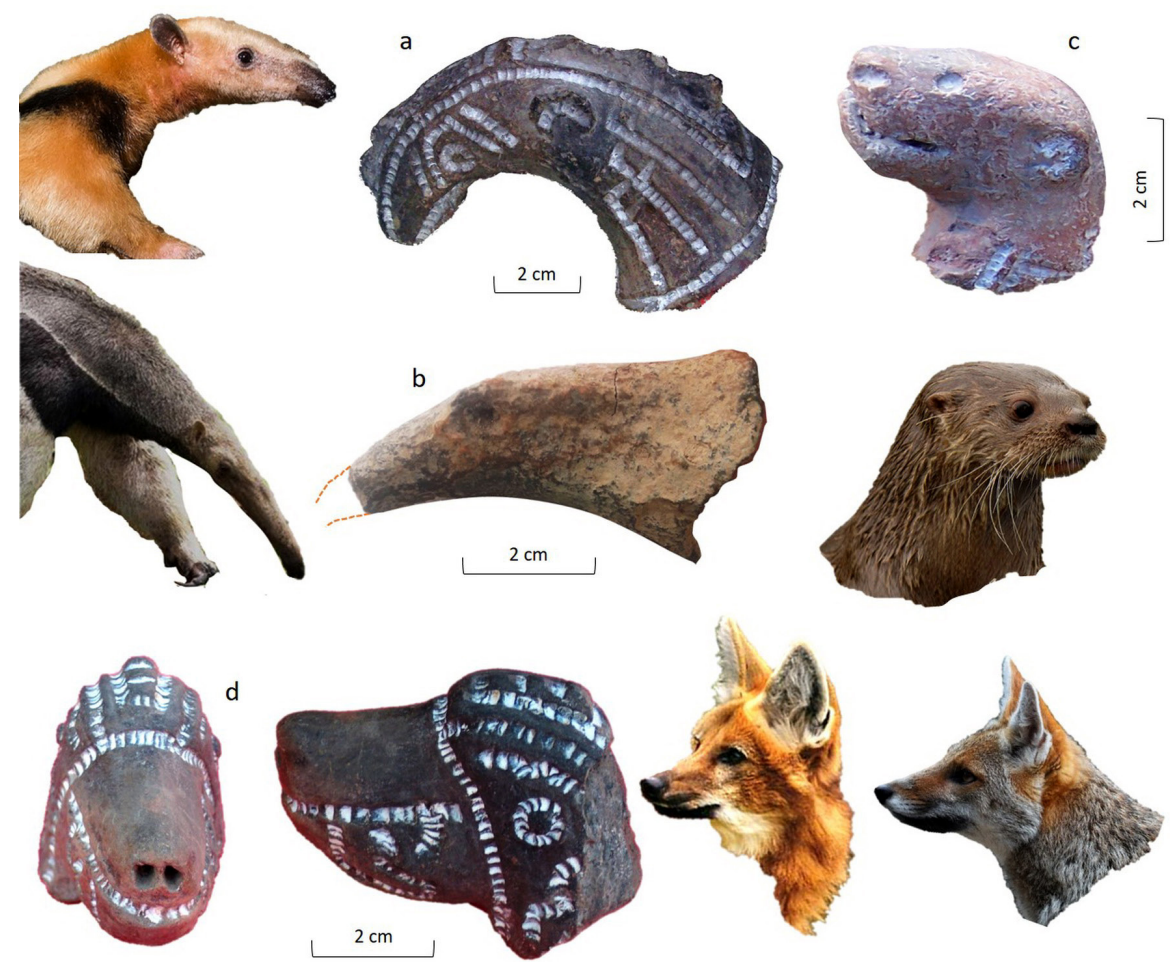

Figura 8. Otros mamíferos representados: (a) Myrmecophagidae del sitio ALM1 (colección Ceruti, Museo Serrano); (b) Myrmecophagidae, Paraná medio (colección privada), arriba: ejemplar de Tamandua tetradactyla, abajo: ejemplar de Myrmecophaga tridactyla; (c) Lontra longicaudis del sitio ALM1 (colección Ceruti, Museo Serrano); (d) Canidae del sitio ALM1 (colección Ceruti, Museo Serrano), derecha: ejemplares de Chrysocyon brachyurus y Lycalopex gymnocercus. La pintura blanca en (a), (c) y (d) no es original.

Other mammals represented: (a) Myrmecophagidae from ALM1 site (Ceruti collection, Serrano Museum); (b) Myrmecophagidae from Middle Paraná (private collection), above: Tamandua tetradactyla specimen, below: Myrmecophaga tridactyla specimen; (c) Lontra longicaudis from ALM1 site (Ceruti collection, Serrano Museum); (d) Canidae from ALM1 site (Ceruti collection, Serrano Museum), right: Chrysocyon brachyurus and Lycalopex gymnocercus specimens. On pieces $(a),(c)$, and $(d)$, the white paint is not original.

y un ejemplar de Cervidae. Teniendo en cuenta las fotografías publicadas por el autor (Serrano 1946:92), la identificación de Tayassu pecarí resulta de todas ellas la más convincente, teniendo en cuenta los rasgos típicos de esta especie, como es la terminación del hocico en forma de disco 5 . Por el contrario, la pieza identificada como Lontra longicaudis no parece exhibir ninguno de los atributos diagnósticos señalados en la Tabla 2 para este animal. El zoomorfo identificado como Ara caraya, por su parte, presenta un hocico alargado, algo aguzado, cuyas características son más concordantes con un cánido que con un primate, ya que estos últimos se distinguen justamente por una disminución de la longitud de sus hocicos. Tampoco resulta totalmente clara la identificación de Puma concolor efectuada por este autor, dado que podría tratarse también de otras especies de felinos locales, como por ejemplo Herpailurus yagouaroundi. A diferencia del puma, el cual posee orejas triangulares, el yaguarundí presenta orejas algo más pequeñas y redondeadas, semejantes a aquellas de la pieza publicada por el autor. Finalmente, el apéndice interpretado por Serrano (1946) como un Cervidae, tampoco exhibe atributos afines a aquellos observables en las tres especies de cérvidos locales (Blastocerus dichotomus, Mazama gouazoubira y Ozotoceros bezoarticus), en relación a la forma de la cabeza, hocico y orejas de estos ungulados. Tampoco se encuentran representados otros rasgos diagnósticos que permitirían la identificación precisa de estas especies, como la cornamenta de los machos. Ante la ausencia de representación de astas, y disponiendo solamente de la representación de la cabeza del 
animal, poder diferenciar entre un cérvido y un camélido como Lama guanicoe (guanaco) se vuelve dificultoso en apéndices realizados con bajo grado de naturalismo, como es el caso de esta pieza.

\section{Los reptiles en la iconografía}

Un grupo minoritario de apéndices se agrupa dentro de la Clase Reptilia. Este macro taxón se identificó fundamentalmente a partir del diseño completo del animal (Tablas 2 y 3, Figura 9). Mayormente corresponden a representaciones de ofidios, los cuales pueden corresponder a una variedad de especies de serpientes y culebras locales. Particularmente en la pieza de la Figura 9a, se distingue una cabeza más ancha y triangular, acorde con las características morfológicas de los ejemplares de la Familia Viperidae, entre los que se incluyen por ejemplo la serpiente de cascabel (Crotalus durissus) y la serpiente yarará (Bothrops alternatus). La mayoría proviene del sitio ALM1, donde Serrano (1946) publicó otros dos ejemplares que no pudieron ser localizados para este trabajo.

El cuerpo de los ofidios se muestra enroscado $(n=6)$ o bien en actitud de desplazamiento $(n=2)$.
Estos últimos no conforman apéndices propiamente dichos, sino que se han realizado mediante pastillaje sobre la superficie externa del recipiente ${ }^{6}$. También para el mismo sitio ALM1 se identificó una representación de tortuga (Orden Testudines), que es la única de las piezas consideradas aquí que no formó parte de un recipiente o de un artefacto "campana", sino que constituye un pendiente. En la Figura 9f puede observarse el orificio del colgante, por medio del cual el animal se posiciona cabeza abajo, donde ésta se encuentra fragmentada.

\section{Registro Artístico versus Registro Arqueofaunístico}

En la Tabla 4 se observa la comparación entre el registro zooarqueológico y el artístico. El primer contraste que surge es la clara predominancia de los peces en los conjuntos faunísticos $(78,7 \%$ del NISP total) y su ausencia absoluta en el arte cerámico. Este mismo patrón es reconocible también en gran parte del registro regional, donde los peces resultan la fracción más numerosa en sitios Goya-Malabrigo (Ceruti y González 2007; Loponte y Acosta 2016; Piccoli et al.
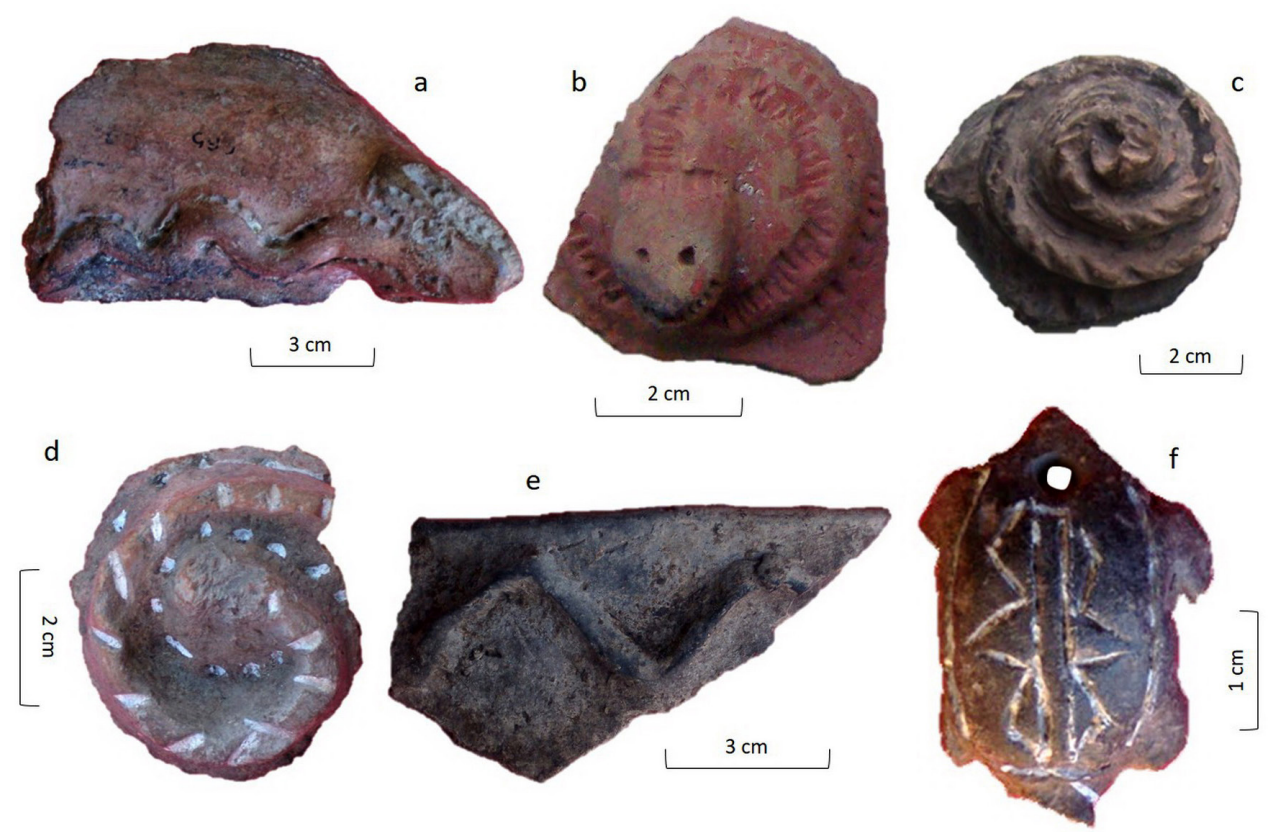

Figura 9. Representaciones de reptiles: (a), (b), (c) y (d) ofidios del sitio ALM1 (a, b y c: colección Serrano, d: colección Ceruti. Museo Serrano); (e) ofidio del sitio AL1 (colección Ceruti, Museo Serrano); (f) tortuga del sitio ALM1 (colección Ceruti, Museo Serrano). La pintura blanca en (d) y (f) no es original.

Reptile representations: $(a),(b),(c)$, and (d) ophidians from ALM1 site ( $a, b$, and c: Serrano collection, $d$ : Ceruti collection. Serrano Museum); (e) ophidian from AL1 site (Ceruti collection, Serrano Museum); (f) turtle from ALM1 site (Ceruti collection, Serrano Museum). On pieces $(d)$ and $(f)$, the white paint is not original. 
2017, entre otros). Los análisis arqueofaunísticos indican que los peces constituyeron el recurso de mayor importancia económica entre los grupos humanos que produjeron este arte cerámico. Esto es avalado también por las mediciones isotópicas realizadas en restos humanos (Ottalagano y Loponte 2017), y es congruente asimismo con los artefactos recuperados en los sitios (p.ej., arpones, anzuelos, pesas de red) que indican un instrumental específico para la actividad de pesca (Ceruti 2003; Ottalagano 2016, 2019a).

La segunda gran discordancia que se observa cuando se confrontan ambos registros, es la significativa abundancia de aves en la iconografía (77,5\% del total de piezas) y su mínima presencia en los conjuntos arqueofaunísticos $(0,31 \%$ del NISP total) (Tablas 3 y 4). Los escasos restos de aves recuperados no evidencian rastros de un potencial aprovechamiento humano, como termoalteración o marcas antrópicas, con lo cual es probable que su presencia en el registro arqueológico se deba mayormente a factores naturales (Ottalagano 2019). Una situación similar es informada también para otros sitios del área de la cuenca media e inferior del Paraná, donde los especímenes de aves se registran igualmente en escasísimo número o bien no se detectan (Bastourre 2014; Bonomo et al. 2014; Píccoli et al. 2017; Sartori et al. 2017, entre otros). Esto es particularmente llamativo, teniendo en cuenta la enorme oferta de especies avícolas que ofrece el ecosistema del Paraná (Olenik y Gavensky 2017). Si se compara las identificaciones de aves en el arte y en los conjuntos zooarqueológicos, se observa por otra parte, una falta de correspondencia entre los taxones mayormente representados en la cerámica y en la arqueofauna (Tabla 4). Una cierta correlación se manifiesta en relación a la Familia Anatidae, cuyos restos óseos fueron detectados por Tonni et al. (1985) en AA1 (sin especificación de NISP), y a la cual se le atribuyeron dos apéndices cerámicos. Probablemente pueda señalarse también el apéndice interpretado por Serrano (1946) como Rhea americana en el sitio ALM1, donde se registró asimismo un solo resto óseo de esta especie: una falange cuyo ingreso al sitio probablemente haya sido resultado del intercambio de pieles y/o tendones (Ottalagano 2019a). Cabe señalar, que el ñandú es fácilmente distinguible en la iconografía cuando se lo diseña con el cuerpo completo, lográndose identificar el largo de su cuello y de sus patas, como sucede en otros casos arqueológicos (p.ej., Recalde y Colqui 2019). Por el contrario, resulta dificultoso la identificación de esta especie a partir solamente de los rasgos presentes en la cabeza, como sucede en el caso puntual de esta figura publicada por Serrano (1946).

Los restos faunísticos asignados a la Clase Mammalia (19,8\% del NISP total) muestran proporciones bastante similares a aquellas cuantificadas en la iconografía (17,5\% del total de piezas). No obstante, como se detalla en la Tabla 4, existe una importante discordancia entre los mamíferos habitualmente consumidos y aquellos representados en el arte. Los análisis zooarqueológicos indican que los pequeños roedores, como Cavia aperea y fundamentalmente Myocastor coipo, tuvieron una significativa incidencia en la subsistencia indígena (Ottalagano 2019a), lo cual es también una marcada tendencia a nivel regional, tanto en contextos Goya-Malabrigo como en otras unidades arqueológicas (Acosta 2005; Acosta y Sartori 2012; Bastourre 2014; Bonomo et al. 2014; Cornero et al. 2007; Santiago 2004; Sartori et al. 2017). Las representaciones de estos pequeños roedores están ausentes en la muestra iconográfica analizada y tampoco hay datos fehacientes que confirmen su presencia en el registro artístico del área. Una situación similar sucede con los ejemplares de Cervidae. Múltiples evidencias indican que éstos fueron consumidos de manera complementaria por los grupos humanos, y que fueron utilizados además, como una fuente de materia prima básica para la confección de instrumentos óseos (Cornero et al. 2007; Mucciolo y Pérez Jimeno 2015; Nóbile 1993; Ottalagano 2019a; Serrano 1946). No obstante, no hay indicios claros que hayan sido representados en el arte.

Una situación inversa se verifica en relación a los ejemplares de la Familia Felidae. Los felinos constituyen el taxón más representado artísticamente entre los mamíferos (Tabla 4), incluyendo especies como el jaguar, de reconocido simbolismo en América precolombina (Gomes 2001; Gordillo 2010; Reichel Dolmatoff 1978). Los pocos datos conocidos respecto a la presencia de restos óseos asignables a felinos entre los materiales arqueofaunísticos provienen del sitio AA1, donde Tonni et al. (1985) mencionan un probable espécimen de Leopardus geoffroyi. En el sitio ALM1, Serrano (1946) reportó particularmente un colmillo de Panthera onca con una perforación en su base, para ser utilizado como colgante, lo que sugiere un probable uso simbólico de las partes del cuerpo de esta especie. En el sitio La Palmera 5, asociado posiblemente a otra unidad arqueológica, Ceruti (2003) registró asimismo una hemimandíbula de $P$. onca con un orificio de suspensión, posiblemente también para un uso ornamental o ritual. 
Tabla 4. Registro arqueofaunístico por sitio y comparación con el registro iconográfico. Archaeofaunistic record by site and comparison with the iconographic record.

\begin{tabular}{|c|c|c|c|c|c|c|c|c|c|c|}
\hline & & & & & queofau & & & & Icono & rafía \\
\hline & Sitio arqueológico & $\mathrm{ALM}^{\mathrm{a}}$ & $\mathrm{ALM1}^{\mathrm{a}}$ & $\mathrm{LP} 2^{\mathrm{b}}$ & $\mathrm{AA} 1^{\mathrm{c}}$ & $\mathrm{AA} 1^{\mathrm{d}}$ & Total & $\pi$ & Total & $\Omega$ \\
\hline Nombre científico & Nombre común & NISP & MNI & NISP & NISP & presencia & NISP & $\%$ & piezas & $\%$ \\
\hline Aves & Ave & 46 & & & & & 46 & 0,3 & 19 & 10 \\
\hline Rhea americana & Ñandú & 1 & 1 & & & & 1 & 0,01 & & \\
\hline Pisttacidae & Loro & & & & & & & & 72 & 37,7 \\
\hline Ara & Guacamayo & & & & & & & & 48 & 25,1 \\
\hline Falconidae & Rapaces diurnas & & & & & & & & 4 & 2,1 \\
\hline Buteogallus coronatus & Águila coronada & & & & & & & & 1 & 0,5 \\
\hline Anatidae & p.ej., Pato & & & & & $\mathrm{x}$ & & & 2 & 1 \\
\hline Chauna torquata & Chajá & & & & & & & & 1 & 0,5 \\
\hline Asio clamator & Lechuzón orejudo & & & & & & & & 1 & 0,5 \\
\hline Eudromia sp. & Perdiz & & & & & $\mathrm{x}$ & & & & \\
\hline Phalacrocorax brasilianus & Cormorán & & & & & $\mathrm{x}$ & & & & \\
\hline Ciconiidae & Cigüeña & & & & & $\mathrm{x}$ & & & & \\
\hline Rallidae & (p.ej. Gallareta) & & & & & $\mathrm{x}$ & & & & \\
\hline Mammalia & Mamífero & 708 & & 56 & 306 & & 1.070 & 8,7 & 15 & 7,8 \\
\hline Carnívora & Carnívoro & 2 & 1 & & & & 2 & 0,02 & & \\
\hline Felidae & Felino & & & & & & & & 7 & 3,6 \\
\hline Panthera onca & Jaguar & & & & & & & & 2 & 1 \\
\hline Leopardus geoffroyi & Gato montés & & & & & $\mathrm{x}$ ? & & & 1 & 0,5 \\
\hline Canideae & p.ej., Zorro, perro, lobo & & & & & & & & 1 & 0,5 \\
\hline Chrysocyon brachyurus & Aguará guazú & 1 & 1 & & & & 1 & 0,01 & & \\
\hline Lontra longicaudis & Lobito de río & & & & & & & & 1 & 0,5 \\
\hline Cervidae & Cérvido & 11 & & & 2 & $\mathrm{x}$ & 13 & 0,1 & & \\
\hline Blastocerus dichotomus & Ciervo de los pantanos & 18 & 1 & & & & 18 & 0,1 & & \\
\hline Ozotoceros bezoarticus & Venado de las pampas & 8 & 1 & & & $\mathrm{x}$ & 8 & 0,06 & & \\
\hline Mazama gouazoubira & Guazuncho & 1 & 1 & & & $\mathrm{x}$ & 1 & 0,01 & & \\
\hline Lama guanicoe & Guanaco & 1 & 1 & & & & 1 & 0,01 & & \\
\hline Cricetidae & p.ej., Ratón silvestre & 8 & & & & $\mathrm{x}$ & 8 & 0,06 & & \\
\hline Ctenomys sp. & Tucu-tucu & & & & & $\mathrm{x}$ & & & & \\
\hline Hydrochoerus hydrochaeris & Carpincho & 30 & 1 & 3 & 2 & $\mathrm{x}$ & 30 & 0,2 & 5 & 2,6 \\
\hline Myocastor coypus & Coipo & 1.158 & 9 & 9 & 38 & $\mathrm{x}$ & 1.205 & 9,8 & & \\
\hline Cavia aperea & Cuis & 188 & 21 & & & $\mathrm{x}$ & 188 & 0,7 & & \\
\hline Myrmecophagidae & Oso hormiguero & & & & & & & & 2 & 1 \\
\hline Dasypodidae & Armadillo & 4 & & & & $\mathrm{x}$ & 4 & 0,03 & & \\
\hline Reptilia & Reptil & 2 & & & & & 2 & 0,02 & 1 & 0,5 \\
\hline Tupinambis merianae & Lagarto overo & 4 & 1 & & & & 4 & 0,03 & & \\
\hline Caiman sp. & Yacaré & 1 & 1 & & & $\mathrm{x}$ & 1 & 0,01 & & \\
\hline Serpentes & Ofidio & & & & & & & & 6 & 3,1 \\
\hline Viperidae & Serpiente & & & & & & & & 1 & 0,5 \\
\hline Testudines & Tortuga & & & & & & & & 1 & 0,5 \\
\hline Peces & $\mathrm{Pez}$ & 7.942 & 174 & 401 & 1.265 & $\mathrm{x}$ & 9.608 & 78,7 & & \\
\hline
\end{tabular}

(a) Ottalagano (2019), (b) Ottalagano et al. (2015), (c) Ottalagno (2016), (d) Tonni et al. (1985).

En el caso de la Familia Canidae, aún no es claro si la representación hallada en ALM1 corresponde a un aguará guazú, a un zorro o a un perro doméstico. Entre los materiales zooarqueológicos de este sitio se identificó un solo espécimen de Chrysocyon brachyurus. Éste corresponde a la porción proximal de un cúbito, con evidencias de aserrado perimetral, lo que podría ser interpretado en función de conductas dirigidas a la obtención de formas base para la confección de instrumentos (Ottalagano 2019a). Para este mismo sitio, Serrano (1946) menciona asimismo el hallazgo de posibles especímenes de cánidos domésticos (sin cuantificar su NISP), especialmente restos de cráneo y de mandíbula; sin embrago, su presencia no ha podido ser corroborada aún en ALM1. Por el contrario, en sitios del Paraná inferior, asociados a otras unidades arqueológicas no incluidas como Goya-Malabrigo, se ha confirmado la presencia de Canis familiaris durante el periodo prehispánico (Loponte y Acosta 2016b). En este sentido, es interesante mencionar el hallazgo, igualmente en sitios del Paraná inferior, de un entierro individual de $C$. familiaris, así como 
de caninos de esta especie que fueron perforados para ser utilizados como pendientes (Acosta et al. 2011; Loponte y Acosta 2016b), lo cual sugiere la inclusión de esta especie en el mundo social y simbólico de los grupos humanos. Por otra parte, en sitios del Paraná inferior vinculados a contextos Goya-Malabrigo, se reportó asimismo la presencia de restos de Lycalopex gymnocercus, así como un húmero distal de cánido con señales de pulimento (Bastourre 2014), lo que podría estar vinculado a un uso tecnológico de estos restos.

El caso del Hydrochoerus hydrochaeris merece una atención especial. Tres de los apéndices identificados como carpinchos provienen del sitio ALM1, donde la cantidad de restos asignables a este gran roedor es muy baja en términos de NISP $(0,3 \%$ del total) y MNI $(0,5 \%$ del total). Las partes esqueletarias registradas para este animal corresponden a elementos del esqueleto axial y apendicular (sin evidencias de modificaciones antrópicas), y especialmente a unidades de la porción distal de éste (p.ej., falanges y metapodios), pudiendo sugerir actividades principalmente de cuereado (Binford 1981). Se detectó una única huella de corte en un astrágalo, que puede ser concordante igualmente con actividades de extracción de la piel. Por otra parte, el registro de dos elementos termoalterados (dos falanges calcinadas), no constituye un indicador confiable de su ingesta (Ottalgano 2019a), ya que es una posibilidad que este proceso térmico esté relacionado con la elaboración de pigmento blanco, dada la detección de hidroxiapatita como fuente de color blanquecino en la cerámica (Ottalagano et al. 2019).

La baja incidencia del carpincho en los conjuntos zooarqueológicos también es un hecho registrado en LP2 y AA1 (Tabla 4), así como en otros sitios de la cuenca del Paraná asociados a distintas unidades arqueológicas (p.ej., Acosta 2005; Cornero et al. 2007; Loponte 2008; Píccoli et al. 2017; Sartori et al. 2017; ver un resumen en Servin 2016), donde también se destaca una representación esqueletaria diferencial de H. hydrochaeris, centrada en falanges y metapodios (Acosta 2005; Acosta y Loponte 2013; Loponte 2008). Algunas excepciones a esto pueden verse en Bastourre (2014) y Santiago (2004). Dentro de los mamíferos, por último, no hay datos que documenten la presencia de ejemplares de Myrmecophagidae ni de Lontra longicaudis en el registro faunístico, como efectivamente sí pueden observarse en el arte cerámico.

Finalmente, un escaso porcentaje de restos faunísticos $(0,06 \%$ del NISP total) y de representaciones
$(4,7 \%$ del total de piezas) han sido atribuidas a la Clase Reptilia (Tablas 3 y 4). Los restos de reptiles identificados en los sitios, como el lagarto overo y el yacaré (Tabla 4), no registran marcas de corte (Ottalagano 2019a). No ha sido posible el reconocimiento de ofidios y testudines en el registro arqueofaunístico de los sitios donde se recuperaron los apéndices zoomorfos, de manera semejante a lo sucedido en el registro regional, donde los reptiles en general están ausentes o se registran en bajísimo número (Bonomo et al. 2014; Cornero et al. 2007; Piccoli et al. 2017; Sartori et al. 2017).

\section{Consideraciones Finales}

En este trabajo se propusieron algunos criterios metódicos, basados en una exhaustiva comparación entre el arte y las morfologías animales del área de estudio, que permitieron identificar con el mayor grado de precisión posible el rango de taxones representados en la cerámica de estilo Goya-Malabrigo, a fin de compararlo con la información zooarqueológica. Los resultados indican una falta de correspondencia entre los principales grupos taxonómicos representados en la alfarería y los restos faunísticos recuperados con mayor frecuencia en los sitios arqueológicos. Esto es especialmente manifiesto en el caso de las aves, que notoriamente abundan en el arte pero tienen una mínima presencia en los conjuntos arqueofaunísticos, no existiendo evidencias notorias de su consumo. Un caso semejante ocurre con los felinos, que son los mamíferos mayormente modelados en el arte, seguidos por los carpinchos. Los escasos restos de Felidae no registran marcas antrópicas o bien corresponden a adornos corporales, lo que sugiere un uso simbólico de partes de su cuerpo, especialmente del jaguar.

El análisis de la presencia de carpinchos en el arte $\mathrm{y}$ en la subsistencia requiere algunas consideraciones. Todas las representaciones de $H$. hydrochaeris que fueron recuperadas en estratigrafía provienen del sitio ALM1, donde los porcentajes de NISP y MNI de esta especie son muy bajos ${ }^{7}$. Una sola huella de corte fue detectada en un astrágalo, la cual podría estar relacionada con la extracción de la piel, pero no hay actualmente datos que sugieran un consumo efectivo de su carne en este sitio. Esto difiere de la información proveniente de otros sitios con cerámica Goya-Malabrigo de la cuenca media del Paraná, donde se han reportado evidencias que indican la explotación económica de este roedor (p.ej., Santiago 2004); por lo cual se hace necesario a futuro profundizar en los 
patrones particulares de representación-consumo de esta especie en los distintos contextos arqueológicos del área. Debe tenerse en cuenta, sin embargo, que la probable restricción cultural del carpincho como recurso alimenticio ha sido mencionada en sitios del Paraná inferior, que no están asociados a ocupaciones Goya-Malabrigo (Acosta y Loponte 2013).

En relación al apéndice identificado como un cánido indeterminado en ALM1, la información zooarqueológica indica la utilización de un resto de aguará guazú como materia prima para la confección de instrumentos, pero aún no hay datos que confirmen la presencia de Canis familiaris en los conjuntos considerados en este estudio. Las restantes representaciones relevadas corresponden a formas zoológicas propias igualmente del ecosistema del Paraná, que no pudieron ser detectadas entre los restos arqueofaunísticos, tales como el oso hormiguero, el lobito de río, la tortuga y los ofidios. Excepto estos últimos que se identificaron en varias piezas, las otras especies parecen constituir representaciones de aparición esporádica en el arte.

Por consiguiente, aquellas formas animales que se encuentran habitualmente representadas en el arte, parecen tener una participación restringida o nula en la subsistencia indígena. Y a la inversa, aquellos taxones que estuvieron involucrados activamente en la economía de las sociedades prehispánicas, especialmente como fuente de nutrientes, están prácticamente ausentes en la iconografía. Tal es el caso de los peces, los cérvidos y los pequeños roedores como el coipo y la cavia. Se registra, entonces, una dicotomía entre los animales representados y los animales cazados/consumidos. Esta oposición no se constata en todos los sistemas iconográficos, dado que algunas investigaciones han reportado coincidencias entre la fauna presente en el arte y aquella que constituyó la base económica de la subsistencia indígena, lo cual podría estar relacionado en algunos casos con un ceremonial propiciatorio para la caza, por ejemplo (Berenguer 1996). Criado Boado y Penedo Romero (1989:5), señalan una importante diferencia conceptual entre un arte que "representa distintas cosas de las que se caza" y otro que "representa lo mismo que se caza". Para estos autores, esta antagonía está relacionada con dos modos distintos de pensamiento, que incluyen maneras diferentes de concebir la relación del ser humano con la naturaleza. $\mathrm{Al}$ analizar comparativamente el arte parietal paleolítico y el postglaciar levantino, los autores constatan una oposición en la forma en que se presenta el arte en uno y otro sistema iconográfico. En el primero, la mayoría de los animales representados no poseen una utilidad económica inmediata. Es un arte que muestra una gran preocupación por plasmar las características etológicas y morfológicas propias de los animales. Aquello que representa tiende a estar distanciado del hombre y de sus labores. En el segundo sistema iconográfico, en cambio, el arte está estrechamente vinculado con la infraestructura material de la sociedad, por lo que los animales representados son económicamente útiles. Es un arte que enfatiza una posición activa del ser humano con la naturaleza, lo cual se traduce en un mayor protagonismo de la figura humana y de sus actividades. Los autores notan, asimismo, que la primer modalidad artística se desarrolla en el propio lugar de asentamiento, en tanto que la segunda se encuentra alejada del espacio doméstico, y relacionada con el espacio de caza. Este caso arqueológico ilustra claramente dos sistemas iconográficos opuestos, que, aunque no se pueden descartar gradientes entre ambos polos, ejemplifican dos formas diferentes de establecer y entender la interacción entre la cultura con el entorno natural. El arte Goya-Malabrigo analizado en este trabajo se aproximaría, entonces, al primer sistema icongráfico referido, en el cual "... se "come" y se "piensa" con animales distintos...", el cual se contrapone a un arte donde "...se "come" y se "piensa" con los mismos animales..." (Criado Boado y Penedo Romero 1989:12). El potencial de considerar de forma conjunta el registro artístico y zooarqueológico de una sociedad radica, por consiguiente, en que este cruce permite evidenciar los modos que una sociedad conceptualiza y simboliza la relación humanos-fauna. Cada sistema iconográfico debería evaluarse, entonces, desde una perspectiva contextual en sentido amplio. Ya que, lejos de ser un fenómeno periférico, aleatorio y pasivo, el arte constituye uno de los dispositivos de representación más importantes que posee una sociedad, siendo un espacio en el que se comparten y comunican significados activos (Hodder 1982a, 1982b; Shanks y Hodder 1998; Wiessner 1983, 1990).

Los resultados arribados en este trabajo, por otra parte, pueden ser tomados como un punto de partida para comenzar a evaluar desde la arqueología, potenciales restricciones culturales en torno al consumo de ciertas especies (Fowles 2008; Insoll 2012; Politis y Saunders 2002). Como señala Zimmermann Holt (1996), el registro arqueofaunístico puede determinar las especies que fueron explotadas para el consumo humano, pero no está en condiciones de explicar porqué otras no lo fueron, aun cuando puedan proveer 
una fuente accesible de alimentos, en cuyo caso el análisis simultáneo de la información zooarqueológica y artística resulta una herramienta fructífera. Un trabajo en proceso está destinado a sistematizar y discutir, justamente, aquellas referencias etnohistóricas y etnográficas regionales que permiten hipotetizar posibles tabúes alimenticios respecto de algunas de las especies representadas (Ottalagano y Colobig 2010; Sánchez Labrador 1910; Techo 1897; Terán 1985, 1998, entre otros), y que podrían ampliar la comprensión acerca de los fundamentos mitológicos por los cuales se seleccionaron ciertos animales por sobre otros, para ser representados en el arte. La interpretación de la iconografía cerámica mediante un abordaje centrado en la analogía etnográfica ha sido desarrollado en otros sectores de las tierras bajas sudamericanas, por autores como Gomes (2007, 2019). Tal abordaje constituye una manera alternativa de pensar las imágenes prehispánicas de acuerdo a categorías nativas y cosmologías amerindias, lo que permitiría interpretar la iconografía de acuerdo a las narrativas mitológicas (Barreto 2009; Gomes 2007, 2019).

Si bien los los resultados aquí presentados sugieren que las formas animales seleccionadas para simbolizar se opondrían a aquellos taxa que tuvieron una finalidad principalmente económica, posteriores estudios permitirán ampliar esta cuestión; así como también, definir la existencia o no de variabilidad espacial en los patrones de representación/consumo de especies. A futuro se hace necesario entonces incrementar la muestra iconográfica identificada, explicitando los criterios metodológicos empleados, a fin que las determinaciones taxonómicas se den en el marco de un acercamiento metódico. Igualmente se deberá sumar nuevos análisis zooarquelógicos y trabajos de campo en el área de estudio, para descartar algún posible sesgo en las proporciones entre animales representados/ consumidos. En definitiva, la posibilidad de identificar con precisión aquellas formas zoológicas que son recurrentemente representadas en el arte, permite explorar los referentes simbólicos utilizados por las sociedades y profundizar en aquellas interacciones humano-fauna que trascienden los roles puramente económicos o nutricionales de los animales.

Agradecimientos: Quiero agradecer a directivos y personal del Museo Regional "Alicia González Castrillón" y del Museo de Ciencias Naturales y Antropológicas "Prof. A. Serrano". Un agradecimiento especial a Carlos Ceruti. También a Víctor Flores, Daniel Loponte, Mario y Daniel Raspini y a la municipalidad de La Paz por toda la ayuda aportada durante los trabajos de campo. Agradezco finalmente a los evaluadores anónimos, cuyos comentarios permitieron mejorar este trabajo.

\section{Referencias Citadas}

Acosta, A. 2005. Zooarqueología de Cazadores Recolectores del Extremo Nororiental de la Provincia de Buenos Aires: Humedal del Río Paraná Inferior, Región Pampeana, Argentina. Tesis Doctoral, Facultad de Ciencias Naturales y Museo, Universidad Nacional de La Plata, La Plata.

Acosta, A. y D. Loponte 2013. Complejidad social y estrategias de subsistencia de las poblaciones cazadoras-recolectoras del humedal del Paraná inferior. Cuadernos del INAPL-Series Especiales 1 (4):60-74.

Acosta, A., D. Loponte y C. García Esponda 2011. Primer registro de perro doméstico prehispánico (Canis familiaris) entre los grupos cazadores recolectores del humedal de Paraná inferior (Argentina). Antípoda Revista de Antropología y Arqueología 13:175-199.

Acosta, A. y J. Sartori 2012. Explotación de Myocastor coypus en el extremo meridional de la cuenca del Plata durante el Holoceno tardío. Revista de Arqueología 24 (2):10-29.

Arbuckle, B. y S.A. McCarty (eds.) 2015. Animals and Inequality in the Ancient World. University Press of Colorado, Colorado.

Arluke, A., C. Sanders y P. Morris 2015. Thinking with animals: the sociology of nonhuman animals and society. En Das MenschTier-Verhaltnis: Eine Sozialwessenschaftliche Einfahrung, editado por F. Theime, R. Brucker, M. Bojok, B. Mutherich y M. Seeliger, pp. 79-105. VS Verlag/Springer, Wiesbaden.

Badano, V. 1946. Sobre algunos ejemplares interesantes de representaciones plásticas. Revista de la Academia de Entre Ríos 1:11-28.

Balfet, H., M.F. Fauvet-Berthelot y S. Monzón 1983. Pour la Normalisation de la Description des Poteries. Edición du Centre-National de la Recherche Scientifique, París.

Barreto, C.N.G.B. 2009. Meios Místicos de Reprodução Social: Arte e Estilo na Cerâmica Funerária da Amazônia Antiga. Tese de Doutorado, Museu de Arqueologia e Etnologia, Universidade de São Paulo, São Paulo.

Bastida, R., D. Rodríguez, E. Secchi y V. Da Silva 2007. Mamíferos Marinos Sudamericanos. Vazquez Mazzini Editores, Buenos Aires.

Bastourre, L. 2014. Estudios arqueofaunísticos en el delta superior del Paraná: el sitio Los Tres Cerros 1 (provincia de Entre Ríos, Argentina). Revista Chilena de Antropología 30 (2):109-115.

Berenguer, J. 1996. Identificación de camélidos en el arte rupestre de Taira ¿Animales silvestres o domésticos? Chungara Revista de Antropología Chilena 20 (1-2):85-114. 
Bernáldez-Sánchez, E. y E. García-Viñas 2019. The equids represented in cave art and current horses: a proposal to determine morphological differences and similarities. Anthropozoologica 54 (1):1-12.

Binford, L.R. 1981. Bones: Ancient Men and Modern Myths. Academic press, New York

Bonomo, M., J. Castro y C. Silva 2014. Tecnología y subsistencia en el sitio arqueológico Cerro Tapera Vázquez (parque nacional pre-delta, República Argentina). Cadernos do LEPAARQ 11 (22):53-81.

Bonomo, M., G. Politis y C. Gianotti 2011. Montículos, jerarquía social y horticultura en las sociedades indígenas del delta del río Paraná (Argentina). Latin American Antiquity 22 (3):297-333.

Burkart R., N. Bárbaro, R. Sánchez y D. Gómez 1999. Ecoregiones de la Argentina. Secretaría de Recursos Naturales y Desarrollo Sustentable, Buenos Aires.

Ceruti, C. 1989. Las modificaciones ambientales del Pleistoceno final Holoceno y su relación con los asentamientos humanos en el noroeste de Entre Ríos. PID-CONICET No 3-81800/88, Informe Final.

Ceruti, C. 2003. Entidades culturales presentes en la cuenca del Paraná Medio (margen entrerriana). Mundo de Antes 3:111-135.

Ceruti, C. 2006. La cerámica de Santa Fe La Vieja: hacia una revaloración del componente indígena. En Santa Fe La Vieja: Arqueología de los Siglos XVI y XVII, editado por M.A. Carrara y N. De Grandis, pp. 1-37. Escuela de Antropología de la Universidad Nacional de Rosario, Rosario.

Ceruti, C. 2017. Relevamiento de las colecciones arqueológicas del museo regional de La Paz. Anuario de Arqueología 9:89-148.

Ceruti, C. 2018. Indicios de complejidad social en la entidad arqueológica Goya-Malabrigo: los enterratorios humanos del sitio la Palmera II (Hernandarias, departamento Paraná, provincia de Entre Ríos, República Argentina). En Goya-Malabrigo, Arqueologia de una Sociedad Indígena del Noreste Argentino, editado por G. Politis y M. Bonomo, pp.149-173. UNICEN, Tandil.

Ceruti, C., O. Fontana, L. López y C. Vesco 1980. Arroyo Arenal 4: Un Hallazgo Arqueológico poco Común. Municipalidad de La Paz, La Paz.

Ceruti, C. y M.I. González 2007. Modos de vida vinculados con ambientes acuáticos del Nordeste y Pampa bonaerense de Argentina. Relaciones de la Sociedad Argentina de Antropología 32:101-140.

Chebez, J.C. 1994. Los que se Van. Especies Argentinas en Peligro. Albatros, Buenos Aires.

Colobig, M.M. y F.V. Ottalagano 2016. Estudio arqueobotánico de los residuos orgánicos adheridos en alfarerías prehispánicas de la cuenca del Paraná medio. Revista Arqueología 22 (1):193-210.

Cornero, S. 2018. En las puertas del mito. Loros y peces en el arte cerámico de la costa del Paraná. En Goya-Malabrigo, Arqueologia de una Sociedad Indígena del Noreste Argentino, editado por G. Politis y M. Bonomo, pp. 89-106. UNICEN, Tandil.

Cornero, S. 2019. Los cóndores andinos del Paraná. Análisis de cerámicas catartidas en la costa del Paraná. Revista Sociedades de Paisajes Áridos y Semi-Áridos 12 (1):138-159.

Cornero, S. y G. Green 2017. Los Mocoretas: entre el indicio y la evidencia. En Ciencia y Tecnología: Divulgación de la
Producción Científica y Tecnológica de la UNR, editado por E. Orellano, pp. 996-1004. Universidad Nacional de Rosario, Rosario.

Cornero, S., F. Solomita y P. Curetti 2007. Componente arqueofaunístico del sitio La Lechuza (provincia de Santa Fe). En Arqueología Argentina en los Inicios de un Nuevo Siglo, editado por F. Oliva, N. de Grandis y J. Rodriguez, pp. 167-171. Labor de Libros, Rosario.

Criado Boado, F. y R. Penedo Romero 1989. Cazadores y salvajes: una contraposición entre el arte Paleolítico y el arte Postglaciar Levantino. Munibe Antropologia - Arkeologia 41:3-22.

De la Peña, M. 2019. Aves argentinas: descripción, comportamiento, reproducción y distribución. Comunicaciones del Museo Provincial de Ciencias Naturales "Florentino Ameghino" (Nueva Serie) 1:1-294.

Flores, P. y M.B. Velárdez Fresia 2018. Las huellas de las aves en las sociedades pasadas: análisis semiótico de representaciones ornitomorfas (Fenómeno Aguada, NOA). Boletín del Museo Chileno de Arte Precolombino 23 (2):59-77.

Foster, M. 1994. Symbolism: the foundation of culture. En Companion Encyclopedia of Anthropology, editado por T. Ingold, pp.366-395. Routledge, Londres.

Fowles, S.M. 2008. Steps toward an archaeology of taboo. En Religion, Archaeology, and the Material World, editado por L. Fogelin, pp. 15-37. Center for Archaeological Investigations (Occasional Paper No. 36), Southern Illinois University, Illinois.

Gaspary, F. 1950. Investigaciones arqueológicas y antropológicas en un "cerrito" de la isla Los Marinos (Dto. Victoria, Entre Ríos) situada frente a Rosario. Publicaciones del Instituto de Arqueología, Lingüística y Folclore 23:3-66.

Gomes, D. 2001. Symbolism and power in the tropical forest. En Unknown Amazon: Culture and Nature in Ancient Brazil, editado por C. McEwan, C. Barreto y E. Neves, pp. 134-155. The Bristish Museum Press, Londres.

Gomes, D. 2007. The diversity of social forms in Pre-colonial Amazonia. Revista de Arqueología Americana 25:189-225.

Gomes, D. 2019. La comprensión de otros mundos. Teoría y método para analizar las imágenes amerindias. Revista Kaypunku 4 (1):69-99

González, R. 1977. Arte Precolombino de la Argentina. Introducción a su Historia Cultural. Imprenta Coni, Buenos Aires.

Gordillo, I. 2009. Dominios y recursos de la imagen. Iconografía cerámica del valle de Ambato. Estudios Atacameños 37:99-121.

Gordillo, I. 2010. La Imagen del Felino en la América Precolombina. Grupo Abierto Comunicaciones, Beccar.

Gradin, C. 1978. Algunos aspectos del análisis de las manifestaciones rupestres. Revista del Museo Provincial 1:120-133.

Hodder, I. 1982a. The Present Past. Pica Press, New York.

Hodder, I. 1982b. Symbols in Action: Ethnoarchaeological Studies of Material Culture. Cambridge University Press, Cambridge.

Insoll, T. 2012. The Oxford Handbook of the Archaeology of Ritual and Religion. Oxford University Press, Oxford.

Iriondo, M. 1991. El Holoceno en el Litoral. Comunicaciones del Museo Provincial de Ciencias Naturales "Florentino Ameghino" 3 (1):1-39.

Iriondo, M., J. Paggi y M.J. Parma (eds.) 2007. The Middle Paraná River. Limnology of a Subtropical Wetland. Springer, Berlin-Heidelberg. 
Layton, R. 1991. The Anthropology of Art. Cambridge University Press, Cambridge.

Lèvi-Strauss, C. 1997. El Totemismo en la Actualidad. Fondo de Cultura Económica, Bogotá.

Loponte, D.M. 2008. Arqueología del Humedal del Paraná Inferior: Bajíos Ribereños Meridionales. Instituto Nacional de Antropología y Pensamiento Latinoamericano (Arqueología de la cuenca del Plata, serie monográfica), Buenos Aires.

Loponte, D. y A. Acosta 2016a. Los contextos Goya-Malabrigo del noreste argentino. Cadernos do CEOM 29 (45)125-187.

Loponte, D. y A. Acosta 2016b. Nuevos Registros de Canis familiaris (Carnivora, Canidae) en la Cuenca del Paraná, Argentina: Mastozoología Neotropical 23:431-454.

Loponte, D., F. Ottalagano, M. Pérez, L. Malec, C. Ramos, P. Bozzano, M. Iribarren, R. Pérez, G. Leiva, S. Domínguez, S. Alí y A. Acosta 2019. Mortuary pottery and sacred landscapes in complex hunter-gatherers in the Paraná basin, South America. Cambridge Archaeological Journal 30 (1):21-43.

Lyman, R. 1994. Vertebrate Taphonomy. Cambridge University Press, Cambridge.

Mashnshnek, C. 1975. Aportes para una comprensión de la economía de los mataco. Scripta Ethnologica 3 (1):7-35.

Masseti, M. 2003. Taxonomic and behavioural aspects of the representation of mammals in Aegean Bronze Age. British School at Athens Studies 9:273-281.

Marean, C. y N. Cleghorn 2003. Large mammal skeletal element transport: applying foraging theory in a complex taphonomic system. Journal of Taphonomy 1:15-42.

Métraux, A. 1935 El universo y la naturaleza a través de las representaciones míticas de dos tribus salvajes de la argentina. Sur 5 (10):54-70.

Métraux, A. 1941 Algunos mitos y cuentos de los Pilagá. Anales del Instituto de Etnografía Americana 3:169-189.

Moreno, E. 2019. Aproximación a la Ontología Candelaria: la Iconografía del Murciélago como Caso de Estudio. Tesis para optar por el título de Arqueólogo, Facultad de Ciencias Naturales e IML, Universidad Nacional de Tucumán, Tucumán.

Morphy, H. 1994. The anthropology of art. En Companion Encyclopedia of Anthropology, editado por T. Ingold, pp. 648685. Routledge, Londres.

Mucciolo, L. y L. Pérez Jimeno 2015. Patrones de consumo final de cérvidos en el Paraná medio: el caso del sitio Cerro Aguará. Revista del Museo de Antropología 8 (1):79-90.

Narosky, T. y D. Yzurieta 2004. Birds of Argentina \& Uruguay. Vásquez Mazzini Editorial, Buenos Aires.

Nóbile, J. 1993. Análisis Arqueofaunísticos del Sitio Arroyo Arenal I, Paraná Medio (Provincia de Entre Ríos). Tesis para optar al grado de Licenciado en Antropología, Facultad de Humanidades y Artes, Universidad Nacional de Rosario, Rosario.

Olenik, N. y M. Gavensky 2017. Lista Comentada de las Aves del Corredor del Río Paraná Inferior. Asociación ornitológica del Plata, Buenos Aires.

Ottalagano, F. 2007. Algunas referencias en torno al simbolismo de las aves en los registros etnohistóricos y etnográficos de guaycurúes y mataco-mataguayos. Arqueología Suramericana 3 (2):213-228

Ottalagano, F. 2008. Hacia la identificación taxonómica de las representaciones de psitácidos en la cerámica de la cuenca del río Paraná. Comechingonia 11:78-98.

Ottalagano, F. 2010. Simbolismo e identidad en las Tierras Bajas del Paraná: un abordaje contextual del arte mobiliar cerámico. Relaciones de la Sociedad Argentina de Antropología 35:195-218.

Ottalagano, F. 2013. Aves Simbólicas, Estilo e Identidad en la Arqueología del Gran Río Sudamericano: Un Estudio Contextual del Arte Cerámico de las Sociedades Prehispánicas de la Cuenca del Río Paraná. Instituto Nacional de Antropología y Pensamiento Latinoamericano (Arqueología de la cuenca del Plata, serie monográfica), Buenos Aires.

Ottalagano, F. 2016. Investigaciones arqueológicas en el sitio Arroyo Arenal I: cuenca media del río Paraná (Entre Ríos, Argentina). Cuadernos del INAPL 25 (2):159-176.

Ottalagano, F. 2019a. Estudios zooarqueológicos en la cuenca Media del Paraná: sitio Arroyo Las Mulas 1 (Entre Ríos, Argentina). Mundo de Antes 13:59-84.

Ottalagano, F. 2019b. Valores de $\delta 13 \mathrm{C}, \delta 15 \mathrm{~N}$ y microrrestos vegetales presentes en residuos de alimentos adheridos en vasijas arqueológicas del sitio La Palmera 2 (Noroeste de Entre Ríos, Argentina). Comechingonia 23 (1):349-364.

Ottalagano, F. 2020. Miniatures as ritual objects: exploring the role of small-sized vessels among the complex Late Holocene hunter-gatherers from the Paraná River lowlands in South America. Cambridge Archaeological Journal 30 (3):433-450..

Ottalagano, F. y M.M. Colobig 2010. Concepciones de aves y felinos en los relatos de un informante chaná: entrevista a Blas Jaime. Revista de la Escuela de Antropología 16:12-24.

Ottalagano, F., M. Darigo, K. Sulich y L. Arelovich 2010. Investigaciones arqueológicas en el Delta superior entrerriano: sitio Cerro Puesto Acosta (Departamento Victoria, Provincia de Entre Ríos). En Arqueología Argentina en el Bicentenario de la Revolución de Mayo, editado por R. Bárcena y H. Chiavazza, pp. 1475-1480. Universidad Nacional de Cuyo, Mendoza.

Ottalagano, F., M. Darigo, B. Pereyra, C. Brancatelli y L. Iannelli 2015. Investigaciones arqueológicas en el sitio La Palmera 2 (cuenca del Paraná medio, provincia de Entre Ríos, nordeste de Argentina). Revista de Antropología del Museo de Entre Ríos 1 (1):55-65.

Ottalagano, F. y D. Loponte 2017. Stable isotopes and diet in complex hunter-gatherers of Paraná River basin, South America. Anthropological and Archaeological Sciences 9:865-877.

Ottalagano, F., M. Reinoso y E. Freire 2019. Análisis químico de pinturas en alfarerías de estilo Goya-Malabrigo. Boletín del Museo Chileno de Arte Precolombino 24 (1):1-15.

Outes, F. 1918. Nuevo jalón septentrional en la dispersión de representaciones plásticas en la cuenca paranaense y su valor indicador. Anales de la Sociedad Científica Argentina 85:53-66.

Pereira, J., D. Varela y L. Raffo 2005. Relevamiento de los felinos silvestres en la región del parque nacional pre-Delta (Entre Ríos, Argentina). Facena 21:69-77.

Píccoli, C. y M.C. Barboza 2018. Las exploraciones de Lilia Spinelli en los inicios de la arqueología en el nordeste argentino. 
En Goya-Malabrigo, Arqueología de una Sociedad Indígena del Noreste Argentino, editado por G. Politis y M. Bonomo, pp. 45-71. Universidad Nacional del Centro de la Provincia de Buenos Aires, Tandil.

Píccoli, C., M. Martín y M.C. Barboza 2017. El registro arqueofaunístico del subtramo Norte de la margen izquierda del Paraná Medio (Corrientes, Argentina). Arqueología 23:35-63.

Politis, G y N. Saunders 2002. Archaeological correlates of ideological activity: food taboos and spirit-animals in an Amazonian hunter-gatherer society. En Archaeological Studies of Material Culture, editado por P. Miracle, pp. 113-130. Mc Donald Institute, Cambridge.

Rangel Estrada, D.A. 2014. Identificación de Zoomorfos en los Materiales Arqueológicos de la Cultura Chalchihuites, Rama Guadiana. Tesis para optar al grado de Licenciado en Arqueología, Escuela Nacional de Antropología e Historia, Mexico D.F.

Recalde, A. y E. Colqui 2019. Las representaciones rupestres zoomorfas en el centro de Argentina y la construcción de identidades (CA. 1500-450 AP). Boletín del Museo Chileno de Arte Precolombino 24 (1):83-104.

Reichel Dolmatoff, G. 1978. El Chamán y el Jaguar. Editorial Siglo XXI, México D.F.

Ryan, K. y P. Crabtree (eds.) 1995. The Symbolic Role of Animals in Archaeology. University of Pennsylvania Press, Pennsylvania.

Sánchez Labrador, J. 1910. El Paraguay Católico. Imprenta Coni, Buenos Aires.

Santiago, F. 2004. Los roedores en el "menú" de los habitantes de Cerro Aguará (provincia de Santa Fe): su análisis arqueofaunístico. Intersecciones en Antropología 5:3-18.

Sartori, J., F. Santiago y B. Colasurdo 2017. El espacio y los recursos: el análisis arqueofaunístico mediante SIG en los distintos ambientes de la provincia de Santa Fe (Argentina) Antípoda Revista de Antropología y Arqueología 28:99-125.

Serrano, A. 1946. Arqueología del Arroyo Las Mulas en el Noroeste de Entre Ríos. Universidad de Córdoba, Córdoba.

Serrano, A. 1961. El arte plástico de los ribereños paranaenses. Nordeste: Revista de la Facultad de Humanidades y Artes 2:73-86.
Serrano, A. 1972. Líneas Fundamentales de la Arqueología del Litoral. Universidad de Córdoba, Córdoba.

Servin, M.C. 2016. Variabilidad en la presencia de carpincho (Hydrochoerus hydrochaeris) en sitios arqueológico vinculados a cuenca del Paraná, en su sector medio e inferior. Anuario de Arqueología 8:101-112.

Shanks, M. e I. Hodder 1998. Processual, postprocessual and interpretative archaeologies. En Reader in Archaeology Theory: Post-Processual and Cognitive Approaches, editado por S. Whitley, pp. 1-28. Routledge, London.

Shepard, A. 1956. Ceramics for the Archaeologist. Carnegie Institution of Washington, Washington DC.

Strahler, A. 1975. Geografía Física. Ediciones Omega, Barcelona.

Techo, N. 1897. Historia de la Provincia del Paraguay de la Compañía de Jesús (Tomo I). Biblioteca paraguaya, Madrid.

Terán, B. 1985. La visión del kiyok en el mundo toba. Suplemento Antropológico 19 (2):9-29.

Terán, B. 1998. Investigación etnográfica: pesca y tabú. Revista Casa Tomada 12:25-28.

Terres, J.K. 1991. Audubon Society Encyclopedia of North American Birds. Wings Books, New York.

Tonni, E., C. Ceruti y M. Iriondo 1985. Los vertebrados del sitio Arroyo Arenal 1, Dpto. La Paz, provincia de Entre Ríos (Argentina). Revista de la Asociación de Ciencias Naturales del Litoral 16 (2):157-167.

Wiessner, P. 1983. Style and social information in Kalahari San projectile points. American Antiquity 48:253-276.

Wiessner, P. 1990. Is there a unit to style. En The Use of Style in Archaeology, editado por M. Conkey y Ch. Hastorf, pp. 105112. Cambridge University Press, Cambridge.

Willis, R. (ed.) 1990. Signifying Animals. Human Meaning in the Natural World. Routledge, London.

Zimmerman Holt, J. 1996. Beyond optimization: alternative ways of examining animal explotation. Word Archaeology 28 (1):89-109.

\section{Notas}

1 En referencia a las figuras ornitomorfas de la cuenca del Paraná, González (1977:416) señala que "las figuras no solo son realistas sino que además están dotadas de expresividad y vida; a veces se tiene la sensación de que se reprodujo a los loros en su momento de excitación, cuando se encrespan las plumas frontales y emiten sus gritos más ásperos (Fig. 358)".

2 Recientemente Cornero (2018) interpretó la presencia de estas líneas incisas como opérculos de peces, de modo tal que los apéndices observables por ejemplo en la Figura 2 y en la Figura 6e, se tratarían, según su interpretación, de figuras duales peces-loros.

3 Esta pieza, que puede ser consultada en Ottalagano (2013), no fue computada en este trabajo debido a que sus rasgos no pueden ser asignados a un único macro taxón.
4 Esta figura fue originalmente interpretada como un posible aguará guazú por Ceruti (com pers. 2006).

5 Ceruti (2017:106) también interpreta como Tayassu pecari un apéndice de la colección del Museo Regional de La Paz. Sin embargo, en este trabajo se consideró a esta pieza como un mamífero indeterminado, por considerarse que no hay elementos suficientes para atribuirlo con certeza a esta especie, debido a que solo se conservó una parte mínima del apéndice original.

6 En este trabajo se computó como una representación ofídica solamente aquellos casos donde se pudo visibilizar la cabeza del animal en la tira de pasta adherida a la superficie, como suceden en las piezas de la Figura 9a y 9b, a fin de no confundirlos con motivos abstractos de pastillaje.

7 La baja presencia de restos de carpincho en ALM1 fue destacada inicialmente por Serrano (1946), aunque sin contabilizar NISP. 